\title{
LA OFICINA ECONÓMICA DEL PRESIDENTE EN \\ EL PRIMER GOBIERNO DE ZAPATERO (2004-2008): PRECEDENTES, ORIGEN Y ALCANCE DE UNA \\ REFORMA IMPREMEDITADA DEL CENTRO PRESIDENCIAL ESPAÑOL
}

\section{The Economic Office of the President in the first Zapatero Government (2004-2008): Precedents, origin and scope of an unplanned reform of the Spanish presidential center}

\author{
FRANCISCO JAVIER LUQUE CASTILLO \\ Universidad de Jaén \\ fluque@ujaen.es
}

MANUELA ORTEGA RUIZ

Universidad de Jaén

moruiz@ujaen.es

Cómo citar/Citation

Luque Castillo, F. J. y Ortega Ruiz, M. (2021).

La Oficina Económica del presidente en el primer Gobierno de Zapatero (2004-2008): precedentes, origen y alcance de una reforma impremeditada del centro presidencial español.

Revista de Estudios Políticos, 193, 249-290.

doi: https://doi.org/10.18042/cepc/rep.193.08

\section{Resumen}

El objetivo principal de este artículo es evaluar el alcance de la conflictividad habida entre la Oficina Económica del Presidente y el ministro de Economía, durante el primer Gobierno de Zapatero (2004-2008). En este sentido nos preguntamos por qué creó Zapatero la Oficina Económica del Presidente, de qué manera la involucró en la toma de decisiones y cómo afectó esto a la autonomía del ministro Pedro Solbes. Para responder satisfactoriamente a las preguntas de investigación se ha combinado el análisis documental con la realización de entrevistas a individuos que, por su implicación directa o por su posición cualificada, podían proporcionar información relevante. Antes de presentar los resultados de la investigación, hacemos un balance de los estudios realizados hasta el momento en Espańa sobre las estructuras de apoyo al 
presidente del Gobierno y encuadramos nuestras indagaciones a partir de las contribuciones realizadas previamente desde la ciencia política acerca del papel de los órganos de asesoramiento económico del presidente, la autonomía del responsable del Tesoro y las implicaciones de las reformas de los core executives. Los hallazgos realizados, coherentes con las ideas asentadas por la literatura especializada, nos permiten afirmar que la Oficina Económica del Presidente como producto impremeditado de la presidencialización solamente socavó la autonomía del titular de Economía de un modo puntual.

\title{
Palabras clave
}

España; Gobierno; centro presidencial; Oficina Económica del Presidente.

\begin{abstract}
The main purpose of this article is to assess the impact of the conflictive relations between the President's Economic Office and the minister of Economy, during the first Zapatero government. According to this we tackle three main research questions: why did Zapatero decide to create that structure, how did he involve it in the decision-making process, and how such actions affected the autonomy of the minister Pedro Solbes. In order to answer them we have combined documentary analysis with interviews to individuals who provided relevant information, given their qualified position or their direct participation in the aforementioned relations. Before presenting the research results, we make a review of the studies made until now on the prime ministerial staff in Spain, framing our inquiries within the contributions made, by Political Science, about the role of the president's economic advisers, the autonomy of the head of Treasury and the implications of reforming the core executive. The findings made, coherent with the ideas posed by the specialized literature, allow us to state that the President's economic office, as an unexpected product of presidentialization, only undermined the autonomy of the minister of Economy exceptionally.
\end{abstract}

\section{Keywords}

Spain; Government; core executive; President's Economic Office. 


\section{SUMARIO}

I. INTRODUCCIÓN. II. LOS CENTROS PRESIDENCIALES EN LA CIENCIA POLÍTICA: EL CASO DE ESPAÑA. III. EL PAPEL DEL CENTRO PRESIDENCIAL EN LAS RELACIONES ENTRE EL PRESIDENTE Y EL MINISTRO DE ECONOMÍA: 1. Los límites a la autonomía del ministro de Economía. 2. El impacto de las reformas de las estructuras de asesoramiento y apoyo de los jefes de Gobierno: los precedentes de Tony Blair y John Howard. 3. El asesoramiento en materia económica dentro de Moncloa: una actividad tradicionalmente conflictiva. 4. Preguntas de investigación, hipótesis y metodología. IV. CREACIÓN Y EVOLUCIÓN DE LA OFICINA ECONÓMICA DEL PRESIDENTE EN EL PRIMER GOBIERNO DE ZAPATERO (2004-2008): 1. Economistas 2004: la galaxia particular de Miguel Sebastián en el universo de la oposición socialista al Ejecutivo de Aznar. 2. De la oposición al Gobierno: un trayecto minado de condicionantes. 3. La Oficina Económica del Presidente se pone en marcha. 4. A medio camino entre un think-tank y una ventanilla para el mundo de las grandes empresas. V. CONSIDERACIONES FINALES. BibLIOGRAFía.

\section{INTRODUCCIÓN}

El estudio del Gobierno desde la ciencia política, durante muchos años entendido como análisis de diferentes dimensiones relativas al órgano institucional identificado — según la latitud- como Gabinete o Consejo de Ministros, acoge desde hace tres décadas una línea de investigación interesada en los agentes y dispositivos que - localizados extramuros de aquel ámbito- apoyan y asisten a quienes desempeñan la posición cimera del poder ejecutivo, llámese primer ministro o presidente. En la experimentación de este cambio resultó decisiva la formulación conceptual del denominado core executive, originalmente concebido para designar a todas aquellas organizaciones y estructuras que fundamentalmente sirven para impulsar e integrar las políticas del Ejecutivo central o para arbitrar en última instancia los conflictos que surjan entre diferentes actores de la maquinaria gubernamental (Dunleavy y Rhodes, 1990: 4). El propósito de los autores que acuńaron este término era trascender un enfoque clásico sobre el estudio del Gobierno, a su juicio agotado, que pivotaba sobre la cuestión acerca del poder del primer ministro frente a los titulares de los distintos departamentos ministeriales.

Hoy día puede afirmarse que tal hallazgo teorético no solo terminó por incorporarse al repertorio conceptual básico de la ciencia política, sino que 
además ha cambiado el lenguaje de quienes tienen por objeto de investigación al Gobierno. Semejante éxito ha tenido que ver seguramente con la vocación deliberadamente neutral y descriptiva de la fórmula, pues invocar al core executive solo implica la asunción de que analizar el poder en la arena gubernamental exige la consideración de una multiplicidad de actores, sin sobreentendidos respecto al tipo de relaciones existentes entre ellos. Dicha maleabilidad no ha tenido su correlato en la adopción de diferentes presupuestos de partida, en la medida que la resource-dependency ha sido el marco teórico preeminente en la literatura especializada. Sin embargo, esta homogeneidad tampoco se ha traducido en una visión unívoca sobre el ejercicio del poder por parte de los integrantes del core executive. Así, mientras algunos estudiosos sostienen que en dicho espacio el poder es relacional y contingente, de tal suerte que no siempre ganan los mismos ni se trata de un juego de suma cero, otros apuntan a la estabilidad decisiva otorgada por las estructuras. Este debate no se ha reproducido fuera del Reino Unido en los mismos términos, si bien la investigación edificada sobre la noción de core executive ha permitido cuestionar las interpretaciones convencionales sobre el Gobierno en varios países de Europa (Elgie, 2011).

Respecto al caso de España, aún son escasos los trabajos motivados por ese afán de ampliar la comprensión del Ejecutivo, en sintonía con los avances registrados por la disciplina en otros lugares. No obstante, en los últimos tiempos se asiste a un renovado interés por los órganos asesores del presidente del Gobierno español como objeto de análisis, evidenciado en la publicación de varias investigaciones que incorporan elementos novedosos en su planteamiento y desarrollo (Garrido y Martínez, 2018; Paniagua, 2018; Rodríguez Teruel, 2020). Este artículo se inscribe en dicha tendencia, abordando un aspecto del primer Gobierno de Rodríguez Zapatero (2004-2008) que atańe a sus estructuras de apoyo, concretamente a las relaciones mantenidas durante aquel período entre la Oficina Económica del Presidente y el ministro de Economía y Hacienda, calificadas como conflictivas tanto por informaciones periodísticas del momento como por posteriores abordajes académicos.

El objetivo principal del presente estudio es evaluar el alcance de dicha conflictividad, partiendo de la premisa de que jefes de Gobierno de todo el mundo en las últimas décadas han acometido reformas de sus sistemas de asesoramiento con el fin de mejorar sus capacidades políticas. En consideración de este presupuesto, nos interrogamos asimismo acerca de las razones que condujeron a Zapatero a promover la creación de la Oficina Económica del Presidente (en adelante OEP), así como al modo en que la involucró en la toma de decisiones. A nuestro juicio, de esta manera estaremos en condiciones de verificar no solo que las relaciones entre los actores mencionados se desenvolvieron en determinado sentido, sino también las lógicas de causalidad 
inductoras de semejante esquema de funcionamiento. Para responder satisfactoriamente a las preguntas que fundamentan esta investigación se ha sometido a análisis tanto evidencia de tipo documental como la proporcionada por varias entrevistas realizadas a individuos implicados en los procesos aquí examinados, o muy próximos a ellos por su posición cualificada.

El artículo se estructura en tres apartados. En el primero de ellos hacemos un balance de los estudios realizados hasta el momento en Espańa sobre las estructuras de apoyo al presidente del Gobierno. En el segundo encuadramos nuestras indagaciones a partir de las contribuciones realizadas previamente desde la ciencia política acerca del papel de los órganos de asesoramiento económico del presidente en las relaciones entre este y el ministro de Economía. La autonomía del segundo es asimismo examinada conceptualmente a partir de los limitados hallazgos generados por la literatura comparada, al igual que las reformas impulsadas por dos jefes de Gobierno de regímenes parlamentarios contemporáneos de Zapatero - Tony Blair y Michael Howard- en sus respectivas estructuras de asesoramiento y apoyo. Las preguntas de investigación que se derivan de tal estado de la cuestión son planteadas tras considerar una serie de precedentes históricos, relevantes por su potencial parcialmente explicativo de los fenómenos sometidos a investigación. El tercer apartado, dedicado a la presentación en clave analítica los resultados de la investigación, dedica dos secciones a contextualizar la creación de la OEP, atendiendo a las circunstancias particulares que explican su alumbramiento.

\section{LOS CENTROS PRESIDENCIALES EN LA CIENCIA POLÍTICA: EL CASO DE ESPAÑA}

La Ciencia Política del mundo hispanohablante no ha sido ajena a la transformación operada en el estudio del Gobierno, a partir de la formulación conceptual del core executive. No obstante, aquella ha registrado un devenir particular marcado por el carácter presidencialista de los regímenes latinoamericanos, al punto de que finalmente cristalizó en castellano el término centro presidencial para señalar a «los núcleos que apoyan directamente la labor de los jefes de gobierno y buscan reforzar su autoridad y su liderazgo, su autonomía y sus recursos políticos, mediante funciones de asistencia y asesoramiento, de coordinación, control político y planeamiento estratégico, articulando dispositivos de centralización y concentración de poderes, en el propio Poder Ejecutivo, frente al Parlamento y en el conjunto de los órganos estatales», incluyéndose "las oficinas de la presidencia, del primer ministro o del canciller, pero también otros agentes e instituciones, formales e informales, que asumen funciones semejantes en el centro de gobierno» (Lanzaro, 2018: 13). 
El análisis politológico de la cúspide del poder ejecutivo español, hasta nuestros días, ha conocido aproximaciones a partir de ambos conceptos. Sin embargo, los hallazgos realizados por una y otra tradición investigadora se complementan entre sí en lo concerniente a la comprensión de los órganos que asisten al premier pues, si bien el centro presidencial es conceptualmente más restrictivo que core executive, en ambas nociones quedan comprendidos aquellos dispositivos ${ }^{1}$. En este sentido, el presente artículo pretende ser una pieza más del puzzle que, desde finales del siglo pasado, llevan configurando distintos estudios sobre las estructuras de asesoramiento y apoyo al presidente del Gobierno de Espańa. Y es que tales trabajos, al margen de su enfoque, han ido contribuyendo acumulativamente a formar una visión de conjunto sólida sobre dichas estructuras, arrojando luz en cada momento sobre varios aspectos decisivos a la hora de explicar la importancia de este elemento en el conjunto del sistema político español.

Las publicaciones iniciales sobre el tema, aún orientadas por una vocación eminentemente descriptiva, acertaron al subrayar la importancia del objeto de investigación casi a la vez que quienes, desde el Reino Unido, promovieron una inflexión en el estudio del Gobierno. Así, a un trabajo fundacional sobre los contornos, las funciones y el funcionamiento del Gabinete de la Presidencia (Ortega, 1991), le siguió no mucho después otro centrado en revelar los cambios organizativos y de personal experimentados en democracia, por dicha institución, con cada relevo en la jefatura del Ejecutivo (Olías de Lima, 1994). En los años 2000 el abordaje politológico de los aparatos de apoyo al premier espańol se problematiza, tratando primero de explicarse su evolución y naturaleza a partir del concepto de presidencialización (Heywood y Molina, 2000); y apuntando después a su papel fundamental en la continuidad de ciertas políticas, independientemente de la alternancia en el Gobierno de distintos partidos (Chari y Heywood, 2009). La última década ha asistido en sus postrimerías a un recobrado interés por estos loci del poder, en la forma de caracterizaciones generales que, además de actualizar la información provista por los estudios originales, se acompañan de una ambiciosa metodología (basada en entrevistas en profundad y escrutinio

1 El centro presidencial comprendería todas las instancias y departamentos adscritos al Gabinete del presidente, la vicepresidencia y las oficinas presidenciales (Paniagua, 2018: 401). El core executive, en los términos definidos por quienes acuñaron el concepto, estaría constituido por una compleja red de instituciones, redes y prácticas en torno al primer ministro, el Gobierno, las comisiones gubernamentales y sus contrapartes que abarcaría desde «clubs» ministeriales oficiosos y comités interdepartamentales, a grandes departamentos como el Tesoro o el ministerio de Asuntos Exteriores, pasando por los servicios jurídicos del Gobierno y los de inteligencia (Dunleavy y Rhodes, 1990: 3). 
de documentación inédita) guiada por el propósito de conocer, con mayor exactitud y profundidad, el funcionamiento del centro presidencial español y las lógicas subyacentes a las transformaciones vividas por el mismo (Paniagua, 2018; Garrido y Martínez, 2018). Un análisis sobre los condicionantes institucionales que operan sobre sus dinámicas internas y relaciones con otros actores se cuenta, asimismo, entre las contribuciones más recientes (Rodríguez Teruel, 2020).

\section{EL PAPEL DEL CENTRO PRESIDENCIAL EN LAS RELACIONES ENTRE EL PRESIDENTE Y EL MINISTRO DE ECONOMÍA}

Afirman Garrido y Martínez, en relación al estudio del gabinete del presidente del Gobierno, que "los trabajos existentes en nuestro país se han referido a los gabinetes de los primeros Ejecutivos de la democracia, por lo que la información disponible no ha sido renovada ni actualizada, o bien han hecho un hincapié muy pronunciado en los aspectos jurídicos, de su regulación, o en los sociológicos, dejando de lado el estudio de su funcionamiento práctico y la influencia política (soft power) que despliegan, además de una discusión en profundidad de su papel en la política española moderna» (Garrido y Martínez, 2018: 165). Semejante juicio, aplicable al centro presidencial en su conjunto, constituye un potente estímulo para interrogarse acerca de aspectos relativos al mismo que, hasta hoy, no han recibido atención suficiente desde la academia. Entre las líneas de investigación que demanda el actual estado de la cuestión descuella, de manera singular, el tema de las relaciones entre el presidente y el ministro de Economía. Y es que, esta parece ser una dimensión sensiblemente afectada por la actividad de las estructuras de asesoramiento y apoyo al jefe de Gobierno, a tenor de algunas observaciones referidas en nuestra escasa literatura.

Hace dos décadas, por ejemplo, Heywood y Molina apuntaban que, pese al aparente predominio formal del presidente, en la toma de decisiones y el funcionamiento del Gobierno también intervenían decisivamente el vicepresidente y el ministro de Economía — calificado por estos autores, de hecho, como «super-ministro». Encontraban una explicación parcial a tal fenómeno en una fuerte compartimentación de la estructura administrativa, coincidente con una delimitación rígida de las competencias y un sistema jerárquico de resolución de conflictos. A resultas de dicho marco institucional desde el departamento de Economía se ofrecían resistencias a colaborar con los asesores presidenciales, percibidos como actores de un rango inferior que además, ejercían de "perros guardianes" (watchdogs) del premier (Heywood y Molina, 2000: 128-129). Sin embargo, en las publicaciones más recientes se dibujan 
escenarios donde la primacía del máximo responsable de las finanzas públicas no está tan clara. Así lo exponen claramente Martínez y Garrido (2018) al aseverar que la pretendida tutela del Gabinete presidencial sobre los ministros genera conflictos cuando los segundos acreditan «una base autónoma de poder o [...] de relación propia con el presidente», como ilustrarían «las continuas discrepancias entre la Oficina Económica de la Presidencia, dirigida por Miguel Sebastián, y el Ministerio de Economía, en la segunda etapa de Solbes, en un amplio espectro de temas, desde la reforma del IRPF a la actitud gubernamental ante distintas OPA, como las de Sacyr sobre BBVA o de Gas Natural sobre Endesa» (Martínez y Garrido, 2018: 180).

En un sentido parecido pero no exactamente igual se expresa Rodríguez Teruel cuando, de un modo más genérico, explica que durante los gobiernos de Aznar, Zapatero y Rajoy, sus respectivos órganos de asesoramiento económico fueron involucrados en el diseño y desarrollo de la política económica, interfiriendo esporádicamente en la actividad del ministerio del ramo (Rodríguez Teruel, 2020: 195). Paniagua, por su parte, añade un nuevo elemento a la ecuación al sostener que si bien «la forma de trabajo y las relaciones entre todas las unidades de asesoría (departamentos) [...] ha seguido el principio de cooperación y no el de competición [...] no han sido tan infrecuentes los choques entre el Gabinete del Presidente (su director) y los ministerios, por ejemplo, especialmente en materia económica, pero no solo (Paniagua, 2018: 413).

De semejante colección de observaciones se colige, en primer lugar, que las relaciones entre las estructuras de apoyo al presidente y el ministerio de Economía son un campo abonado para el conflicto. En segundo lugar, se desprende asimismo que dichas relaciones han experimentado cambios a lo largo de las últimas décadas, pues se ha transitado aparentemente desde un modelo de fuerte autonomía del titular de Economía, a otro en el que se reconoce más protagonismo a los órganos asesores del premier. Ambas apreciaciones, conjuntamente consideradas, exigen nuevas indagaciones que proporcionen evidencias para clarificar cómo ha evolucionado el centro presidencial español, por qué lo ha hecho, y en qué medida dichas transformaciones han afectado al funcionamiento del core executive, y más específicamente a la autonomía del ministro de Economía. El abordaje de estas interrogantes es coherente con la agenda de investigación española sobre las estructuras de apoyo al jefe de Gobierno, que casi sin excepción ha alumbrado estudios con un enfoque diacrónico preocupados por la cuestión de la presidencialización, entendida como multiplicación o ampliación de los instrumentos de poder a disposición del primer ministro, para la satisfacción de sus objetivos e intereses sin delegar en terceros, sorteando así eventuales resistencias a su voluntad (Poguntke y Webb, 2005: 5-8). 
No obstante, atendiendo a esa demanda de profundización planteada por algunos colegas, en estas páginas se propone dar respuesta a las referidas inquietudes con un estudio de caso que nos permita ampliar el foco y, por tanto, no solo reconstruir los procesos de cambio sino también identificar las dinámicas de causalidad subyacentes y su impacto sobre la toma de decisiones. La experiencia gubernamental tomada como objeto de estudio por el presente trabajo es el primer Ejecutivo encabezado por el socialista José Luis Rodríguez Zapatero (2004-2008), que promovió una reforma de sus estructuras de asesoramiento y apoyo — con la creación de la $\mathrm{OEP}$ — de efectos limitantes en la autonomía del ministro de Economía - a tenor de lo afirmado por Garrido y Martínez (2018: 180), a su vez congruente con algunas informaciones periodísticas publicadas en aquel período.

\section{LOS LÍMITES A LA AUTONOMÍA DEL MINISTRO DE ECONOMÍA}

La autonomía del ministro de Economía es otro tema que, como el del centro presidencial en nuestro país, tampoco ha concitado un interés significativo por parte de la ciencia política. Además, el estudio de dicha cuestión se ha sustanciado a partir de la noción de influencia, un concepto relacionado pero no exactamente equivalente. Así, no encontramos el primer abordaje centrado en esta figura hasta 1991, año en que Jean Blondel publica Ministers of finance in Western Europe: A special career? En este trabajo, el politólogo francés examinó de manera agregada las carreras políticas de 218 titulares del Fisco, al objeto de comprobar si el cursus honorum de este tipo peculiar de dirigente respondía a un patrón diferenciado respecto al conjunto de los ministros que explicara su posición preeminente dentro del Ejecutivo. Para evaluar el impacto de la carrera política en la influencia, el profesor galo tomó en consideración cuatro aspectos: antecedentes ocupacionales, duración en el puesto, experiencia previa como ministro de Economía, y presencia o ausencia en el Gabinete de predecesores en el cargo (Blondel, 1991: 8).

La investigación de Blondel arrojó como primera conclusión que, comparadas las distintas muestras nacionales, no se apreciaban pautas comunes en las carreras políticas de los titulares del Tesoro de Europa Occidental, con una excepción: aproximadamente la mitad de todos ellos podían considerarse especialistas (una cifra mayor que la observada para el universo de los ministros habidos en el período sometido a examen). Por lo demás, el background político de los responsables del Fisco y su duración promedia en el cargo conocía expresiones dispares según el país que se tratara. Aun así, el autor sugirió que los ministros de Finanzas podían ser clasificados en cuatro categorías: los muy influyentes en el Gabinete, a resultas de su prolongada 
permanencia en el mismo, con un perfil deespecialista (Alemania) y/o habiendo desempeñado previamente otros puestos ministeriales (Suecia); aquellos que ejercen bastante influencia, atemperada no obstante por una menor duración al frente de tales responsabilidades (Austria y Holanda); los moderadamente influyentes, como consecuencia de su especialización estándar o baja, así como de una carrera ministerial relativamente corta en el tiempo (Reino Unido, Irlanda e Italia), y quienes tienen una posición débil en el seno del Ejecutivo, pues su paso por el Gobierno es efímero, su experiencia ministerial previa inusual y su nivel de especialización pobre (Finlandia) (ibid.: 27-32).

La influencia del ministro de Economía volvió a ser objeto de análisis en un trabajo que vio la luz solo dos ańos después de que lo hiciera el estudio de Blondel, precisamente como resultado de un ambicioso proyecto de investigación - encabezado por este mismo autor junto a Ferdinand Müller-Rommelen el que se indagaba acerca de distintas facetas de la vida interna de los Gabinetes en Europa Occidental (las reglas bajo las que operan, el papel de los partidos, el rol de los ministros y primeros ministros, etc.). En el capítulo dedicado a los responsables del Tesoro (Larsson, 1993), además de volver sobre las variables ya exploradas por Blondel, se realiza una exposición sistemática de los actores que eventualmente pueden limitar el margen de maniobra de los ministros de Economía (el jefe del Ejecutivo, otros ministros económicos, los intereses privados, los bancos centrales, los altos funcionarios, etc.). A partir de los hallazgos realizados en el plano empírico, así como en la revisión de la literatura sobre el Gobierno producida en cada país, Larsson acomete una caracterización general de los titulares del Fisco, sin dejar de atender a las peculiaridades registradas en cada nación. A este respecto, y tras constatar que los ministros de Economía no son ministros «ordinarios», el autor concluye que su grado de influencia no parece estar relacionado con la estructura organizacional del Gobierno (Larsson, 1993: 221).

Esta investigación tuvo su réplica para los países de Europa del Este una década después, a cargo también de Blondel y Ferdinand Müller-Rommel, acompañados además en esta ocasión por Darina Malová. Sus resultados, que no se harían públicos hasta 2007 , reprodujeron en gran medida las observaciones realizadas respecto a los Gabinetes del hemisferio occidental, de tal suerte que el responsable de Economía emergía de nuevo como una figura preeminente en relación al resto de ministros, hasta el punto incluso de proyectar un organigrama gubernamental de tres niveles, donde el titular del Tesoro ocupaba un posición intermedia entre la cúspide (representada por el primer ministro, PM) y la base (integrada por el resto de ministros). Semejante superioridad habría de tener su origen en varios fenómenos, constituyendo la importancia del proceso presupuestario, así como las restricciones 
impuestas por este a los titulares de las diferentes carteras, dos de los más relevantes (Blondel et al., 2007: 176).

Esta observación reaparecería en las conclusiones de un trabajo, realizado a partir de una exhaustiva revisión de literatura biográfica, en el cual se trataban de sistematizar las cualidades personales, profesionales y políticas que, a lo largo del siglo xx habían actuado como fuentes de influencia de los ministros de Economía en Irlanda y Reino Unido. En este sentido, los autores de dicha investigación terminan subrayando la importancia de la estrategia presupuestaria desarrollada por el responsable del Fisco, de las policy choices, en la consolidación y acrecentamiento de su liderazgo (Considine y Reidy, 2008: 81). De esta contribución cabría destacar no solo el tratamiento cualitativo de la información recabada - que encuentra expresión en el relato de episodios historiográficamente fundamentados—, sino también el interés por ilustrar aquellas situaciones en las que la influencia del ministro de Economía experimenta un menoscabo, en beneficio de actores tales como el PM, otros integrantes del Gabinete o los altos funcionarios del ministerio. Semejante enfoque puede considerarse deudor de Larsson, quien ya estableció que la relación entre un jefe de Gobierno y su responsable de Economía puede verse afectada por el background del primero (en la premisa de que este, si ha estado al frente del erario público o cuenta con una experiencia formativa o política en economía, tenderá a involucrarse en los asuntos relativos al Fisco); por la composición partidaria del Ejecutivo (pues en uno de coalición, los márgenes de maniobra del PM y del ministro de Economía se verán notablemente restringidos si provienen de partidos distintos), o por el nivel de expertise en materias económicas de sus respectivas estructuras de apoyo (Larsson, 1993.: 210-211).

La idea de un ministro de Economía cuya influencia no solo deriva de sus propias cualidades, sino también de arreglos institucionales o de la acción de otros actores, es asimismo compartida por varios autores que, tras estudiar el papel desempeñado por el Tesoro británico en el terreno del policy-making, perciben más ajustada a la realidad la imagen de un Fisco interdependiente, sometido en su actividad a restricciones de diversa índole, que no puede comportarse de modo unilateral ni invocar la jerarquía para imponer sus criterios (Thain y Wright, 1995; Deakin y Parry, 2000). Esta visión, de algún modo conflictiva con la del primer Blondel, demanda nuevos abordajes de la influencia del ministro de Economía, si bien desde un ángulo menos preocupado por identificar sus fuentes que por comprender sus límites. En este sentido, el estudio de la OEP durante el primer mandato de Zapatero puede proveer de claves que ayuden a interpretar mejor los procesos gubernamentales que involucran, en mayor o menor medida a esta figura tan invariablemente singular en todos los Ejecutivos. 


\section{EL IMPACTO DE LAS REFORMAS DE LAS ESTRUCTURAS DE ASESORAMIENTO Y APOYO DE LOS JEFES DE GOBIERNO: LOS PRECEDENTES DE TONY BLAIR Y JOHN HOWARD}

Dados los presupuestos avanzados en el anterior apartado se impone, a la hora de ponderar los límites ejercidos por el PM a la autonomía de su responsable de Economía, examinar el impacto producido — en la relación entre ambos actores - por las transformaciones ocurridas en las estructuras de asesoramiento y apoyo de aquel. En un estudio llevado a cabo sobre este tipo de instancias en doce países diferentes, publicado bajo el nombre Administering the Summit: administration of the core executive in developed countries (Peters et al., 2000), se llegó a la conclusión de que dichas estructuras venían acusando en los últimos tiempos un cuádruple proceso de crecimiento, institucionalización, politización e hibridación. El crecimiento encontraría una elocuente manifestación en el incremento de recursos a disposición del PM, principalmente - aunque no solo- personal llamado a desempeñar tareas de la más diversa índole. La institucionalización tiene que ver con la estabilidad de los arreglos organizativos acometidos para dotar de más y mejores medios a las personas al frente de los puestos clave del core executive. La politización aludiría al reclutamiento de cuadros del partido o de grupos de presión afines, a la cooptación de altos funcionarios claramente identificados con el partido gobernante, a la subordinación de altos funcionarios neutrales a las políticas más partidistas o a las tres cosas a la vez. Por último, la hibridación designa la confusión de las fronteras entre las distintas fuentes de apoyo y asesoramiento (Tiernan, 2006: 321-322).

Estudios de caso publicados pocos años después sobre jefes de Gobierno de regímenes parlamentarios parcialmente contemporáneos de Zapatero confirmaron en términos generales las tendencias referidas más arriba. Así, por ejemplo, en el caso del Reino Unido durante la era Blair el crecimiento de las estructuras de apoyo y asesoramiento del PM se habría sustanciado mediante la creación de nuevas instancias dentro del organigrama gubernamental, pero también a través de la transferencia incremental de recursos económicos y de personal al core executive generalmente considerado y a ciertos órganos en particular (Burch y Holliday, 2004: 4-10). Aunque aparentemente no conoció una expansión homologable, el Gobierno del australiano Howard también registró un aumento progresivo en el número de individuos empleados, deriva que tuvo un especial impacto en la Media Unit (que nunca había contado con tanto personal). Asimismo, se alumbraron nuevos órganos como la Cabinet Policy Unit, a la cual se atribuyó un papel clave en el funcionamiento del Ejecutivo (Tiernan, 2006: 317-322).

En lo tocante a la institucionalización parecería que la experiencia británica en los años del New Labour no se ajustó con rigor a dicha pauta, habida 
cuenta de que algunos de los cambios organizativos introducidos en la primera legislatura de Tony Blair fueron revisados tras la nueva victoria laborista de 2001. Sin embargo, aunque no existió una completa estabilidad en las transformaciones experimentadas en un primer momento por las estructuras de apoyo y asesoramiento al PM, sí hubo coherencia con la orientación de las reformas emprendidas cuatro años atrás, pues en todo momento se buscó una mayor eficacia en el funcionamiento del Prime Minister Office y del Cabinet Office, con el objeto de fortalecer al PM y su entorno (Heffernan, 2003: 361-362; Burch y Holliday, 2004: 8-10). En el caso del australiano Howard, la institucionalización sí se sustanció en la permanencia inalterada del esquema organizativo de asesoramiento y apoyo pergeñado tras la asunción del poder, basado fundamentalmente en tres pilares: el Prime Ministerial Office, la Cabinet Policy Unit y el Department of Prime Minister and Cabinet (Tiernan, 2006: 313).

Respecto a la politización, de los análisis de estos autores parece desprenderse que no fue un fenómeno central en las estrategias de autorreforzamiento que, impulsadas por Blair y Howard, pasaban por la reforma de sus respectivas estructuras de asesoramiento y apoyo. De hecho, la identidad de los individuos escogidos para encabezar las distintas unidades del organigrama gubernamental (ya fueran unipersonales o colegiadas, antiguas o de nuevo cuño), antes que preferencia por los compañeros de partido revela cierta inclinación a asignar responsabilidades sobre la base de la confianza personal. Según Tiernan, que la personalización desplace parcialmente a la politización en los procesos de transformación de tales estructuras es un rasgo típico de los sistemas políticos de tipo Westminster. La personalización encuentra su principal plasmación en el nombramiento de los integrantes del estrato directivo del core executive, reclutados a partir de criterios tales como el común background o estilo con el PM, la sintonía o alineamiento ideológico con la dirección que se quiere imprimir a las políticas gubernamentales,o el haber tenido una relación personal previa con el premier (ibid.: 322). Sin embargo, la personalización no solo incide en la lógica de reclutamiento de los altos cargos del core executive, sino que también afecta a veces a su diseńo mismo.

Así ocurrió al menos con Blair, que llevó al Gobierno consigo a quien había sido su jefe de Gabinete en la oposición, Jonathan Powell, y a quien hasta entonces se había probado como su asesor más próximo, Peter Mandelson. Con la incorporación de ambos a la estructura de apoyo del PM, el líder laborista ya puso en evidencia la importancia que le concedía a las relaciones personales, empero el alcance de la personalización fue más allá de los nombramientos y se adentró en el terreno organizativo, pues si para el primero creó el nuevo cargo de jefe de personal (chief of staff) en el seno del Prime Ministerial Office, al segundo lo ubicó en el Cabinet Office como ministro sin 
cartera (Burch y Holliday, 2004: 5). Al menos aparentemente, el componente de la personalización estuvo ausente en las transformaciones organizacionales impulsadas por Howard en su sistema de asesoramiento; no obstante, está acreditada la predilección que tuvo el premier liberal a la hora de conformar su equipo al más alto nivel por individuos con los que compartía relaciones de diversa índole (a veces incluso familiares). Ejemplo de esto último lo constituye la elección como cabinet secretary de Michael L'Estrange, un cercano colaborador de Howard en la campaña electoral que le aupó al poder en 1996. Otro tanto puede decirse del nombramiento de Max Moore-Wilton como secretary of prime minister and Cabinet, al que Howard llamó a su lado para ejecutar liderar la implementación de una agenda radical de reformas en el sector público (Tiernan, 2006: 312).

Finalmente, a tenor de las observaciones realizadas por los autores mencionados, las estructuras de asesoramiento y apoyo de Blair y Howard tampoco permanecieron ajenas, en sus respectivos procesos de reforma, al fenómeno de la hibridación. Así lo afirman Burch y Holliday, quienes constataron que la primera oleada de transformaciones sufridas por el core executive británico en los años del nuevo laborismo acabaron alumbrando un aparato gubernamental excesivamente complejo que propiciaba la duplicidad de funciones y esfuerzos. Tal solapamiento habría tenido su origen en las confusas relaciones entre la Policy Innovation Unit y la Forward Strategy Unit, en la falta de claridad en lo relativo al papel de la Delivery Unit del PM respecto a los departamentos y el Tesoro, o en la indefinición a la hora de asignar la responsabilidad de controlar la consecución de objetivos (Burch y Holliday, 2004: 10). La hibridación se habría materializado de un modo diferente en los Gobiernos comandados por el liberal Howard, con la edificación de un sistema de asesoramiento en el que se ubicaban al mismo nivel una instancia de extracción burocrática como el Cabinet Secretariat, y otra de composición partidista como el Cabinet Policy Unit. Empero, semejante configuración no resultó de manera impremeditada, sino que reflejaba las opiniones del propio Howard sobre la hibridación, a la que concedía un efecto positivo en la medida que se ponía al servicio del Gobierno el mayor rango posible de habilidades, tanto políticas como administrativas (Tiernan, 2006: 322).

En definitiva, tanto Blair como Howard acometieron estrategias de autorreforzamiento político que conllevaron la reforma de sus respectivas estructuras de asesoramiento y apoyo, las cuales atravesaron por un cuádruple proceso de crecimiento, institucionalización, personalización e hibridación, como consecuencia de aquellas estrategias. En ambos casos, tal proceder se tradujo en una mayor eficacia de sus aparatos gubernamentales y, por extensión, en un incremento de su capacidad de influencia. En la medida que el jefe de Gobierno aparece como uno de los límites más importantes que puede 
encontrar el ministro de Economía (según vimos en el anterior apartado), de las reformas de sus estructuras de asesoramiento y apoyo no cabe esperar otra cosa que un reajuste en las relaciones de poder entre todos los actores implicados. Discernir la naturaleza y el sentido de dicho reequilibrio es el propósito de la investigación, aquí introducida, sobre el alcance de la conflictividad habida entre la OEP y el titular de Economía durante el primer Gobierno de Zapatero.

\section{EL ASESORAMIENTO EN MATERIA ECONÓMICA DENTRO DE MONCLOA: UNA ACTIVIDAD TRADICIONALMENTE CONFLICTIVA}

A la hora de abordar la conflictividad entre actores políticos se impone evitar atajos argumentativos que hagan descansar el análisis, exclusivamente, sobre interpretaciones de corte psicológico basadas en variables tales como la personalidad o la ambición. Y ello no solo porque adoptar semejante enfoque obliga a desarrollar una metodología de difícil implementación, sino porque los procesos políticos son invariablemente un producto de la interacción entre los individuos y las normas prevalecientes en un contexto dado. Si las segundas acreditan además una cierta continuidad a través del tiempo con otras disposiciones que las precedieron, el fenómeno sometido a estudio quizá se revele - siquiera parcialmente- como la expresión particular de un patrón histórico. En este sentido, no podemos dejar de integrar en nuestra aproximación a la OEP una revisión de la manera en que, hasta su creación, se había desenvuelto el asesoramiento económico dentro de Moncloa.

Por tanto, conviene empezar seńalando que el Departamento de Asuntos Económicos del Gabinete de Presidencia nació con la Ley 10/1983 de Organización de la Administración Central del Estado (LOACE), cuya entrada en vigor significó la instauración de un entramado organizativo de apoyo al presidente que, además del Ministerio de Presidencia, la Oficina del Portavoz del Gobierno y la Secretaría General de Presidencia, contemplaba la creación de un Gabinete "como órgano de asistencia política y técnica» (art. 6 LOACE). El Gabinete se dividió en ocho departamentos sectoriales (Asuntos Institucionales, Defensa y Seguridad, Asuntos Sociolaborales, Economía, Internacional, Educación y Cultura, Análisis y la «línea caliente», compuesta de un Servicio de Programas y otro de Comunicación con los Ciudadanos), en lo que constituyó un ejercicio de reforma administrativa inspirado por la reciente experiencia de los Gobiernos socialdemócratas en Alemania. Hasta entonces, y tomando como punto de partida el primer Gobierno de Adolfo Suárez en 1976, el sistema de asesoramiento y apoyo al presidente se había caracterizado por su reducido tamańo y moderada complejidad estructural, pues lo integraban un jefe de Gabinete, una Dirección General de Organización y otra de 
Estudios, y un secretario de Gabinete. En la práctica, las direcciones generales se ocupaban, respectivamente, de los asuntos internacionales y económicos (Olías, 1994: 259-265) ${ }^{2}$.

La creación de un Departamento de Economía en el seno del Gabinete presidencial supuso un punto de inflexión en la institucionalización del asesoramiento al presidente en materia económica, que hasta entonces había tenido lugar de un modo cuanto menos críptico. Empero, además de dicha tarea de asesoramiento, a esta instancia se le atribuyeron otras dos funciones relacionadas: el seguimiento de los ministerios económicos (Economía y Hacienda, Industria, Comercio y Turismo, Agricultura, Pesca y Alimentación, y Obras Públicas y Transportes) e informar sobre la actividad de los agentes económicos (banca, empresas de seguros, organizaciones empresariales, etc.) (Ortega, 1991: 222). Las facultades reconocidas a esta sección del Gabinete presidencial fueron aprovechadas por el número dos del PSOE, Alfonso Guerra, durante los años que compatibilizó aquella condición con la de vicepresidente del Ejecutivo (1982-1991) para fiscalizar críticamente las políticas impulsadas desde el Ministerio de Economía y Hacienda, primero por Miguel Boyer (1982-1985) y luego por Carlos Solchaga (1985-1993), que por lo general juzgaba como «excesivamente liberales». La instrumentalización que hizo Guerra del Gabinete del presidente globalmente considerado, convertido en una suerte de Gobierno paralelo, fue posible en la medida que la LOACE configuraba una misma estructura de asesoramiento y apoyo para el presidente y el vicepresidente, y por la circunstancia adicional de que Felipe González nunca mostró interés por aquella (Ortega, 1991: 201; Aizpeolea, 2004: 80).

Así, que el Departamento de Economía del Gabinete de Presidencia fuera un foco de tensión en relación con el Ministerio de Economía y Hacienda tenía mucho que ver con la personalidad y el perfil ideológico de Alfonso Guerra. No obstante, aquel era asimismo un fenómeno favorecido por el propio diseño institucional del centro presidencial y por el desinterés del jefe de Gobierno hacia su estructura de asesoramiento y apoyo, pues ambos elementos permitieron al vicepresidente la instrumentalización del Gabinete. Desde esta perspectiva se comprende que una vez cesados Alfonso Guerra y su responsable de asuntos económicos en el Gabinete de Presidencia, Francisco

2 Se evitó adjudicar a las direcciones generales un nombre que remitiera a sus funciones reales, para eludir así problemas de competencias con otros órganos de la Administración. Por otro lado, el ascenso de Leopoldo Calvo-Sotelo a la Presidencia del Gobierno trajo consigo una devaluación del Gabinete, del que se independizaron el secretario (ahora convertido en Secretaría General) y la Dirección de Estudios (Olías, 1994: 259-260). 
Fernández Marugán, la red institucional de apoyo al premier continuara siendo una fuente de fricciones respecto al Fisco. Así lo atestigua una de las personas entrevistadas para esta investigación, Enrique Guerrero, que apunta a Narcis Serra (sucesor de Guerra como segundo del Gobierno socialista), a Antonio Zabalza (nombrado director del Gabinete de Presidencia tras más de dos años de mandato vicepresidencial de Serra) y a Pedro Solbes (titular del Tesoro en la última legislatura de la era González), como los nuevos protagonistas de una relación triangular cuya naturaleza conflictual venía de atrás.

En consideración de estos antecedentes no ha de resultar extrańo que la formación del primer Gobierno del Partido Popular (PP) en mayo de 1996 constituyera el inicio de un capítulo más en las potencialmente complejas relaciones entre el Ministerio de Economía y el entorno de Presidencia del Gobierno. Tal cosa sucedió a resultas de la iniciativa personal del nuevo jefe de Gobierno, José María Aznar, de crear una Oficina Presupuestaria adscrita a Presidencia, una propuesta que en el programa electoral del PP ( $«$ Con la nueva mayoría») se enmarcaba dentro de las llamadas a facilitar la contención del gasto público. En su planteamiento original esta Oficina se anunciaba simplemente como un recurso concebido para permitir «un mejor seguimiento y control de las iniciativas de los distintos Departamentos». Sin embargo, a la hora de su materialización se reveló como algo más que una instancia de estudio y monitoreo de la actividad desarrollada por los ministerios.

Semejante deriva la anticipaba de alguna manera el perfil de la persona escogida para dirigirla, el septuagenario catedrático de Hacienda José Barea, conocido en las altas esferas como Míster No por su firme y sistemática aversión a la realización de gastos no programados cuando era un mandarín del Fisco $^{3}$. No obstante, aparte de su insobornable rigor en la fiscalización de las finanzas estatales, Barea y su Oficina del Presupuesto devinieron en una fuente de tensiones dentro del centro presidencial por la vocación que tenía el primero de sugerir alternativas políticas difícilmente compatibles o abiertamente contradictorias con el discurso del PP y el Gobierno Aznar. El riesgo de proyectar la imagen de que no había un criterio unificado en el Ejecutivo sobre muchos temas, sumado al daño generado a la credibilidad del ministro de Economía Rodrigo Rato (dadas las duras críticas dispensadas a las cuentas públicas desde la Oficina del Presupuesto $)^{4}$, seguramente terminó por convencer a Aznar de la necesidad de dar por terminado el paso de Barea por Moncloa

3 Franco Oliván, J. A. (1996). «Barea: "Vamos a tapar todos los agujeros"». ABC, 13-051996.

4 «El Gobierno "destapa” otro informe de Barea que avala el presupuesto». El País, 24-10-1997. Disponible en: https://bit.ly/3jqjDBO. 
menos de dos años después de su nombramiento. No obstante, oficialmente se dijo que el cese del veterano profesor se había producido de común acuerdo con este, después de que se hubieran alcanzado los objetivos de rigor presupuestario y reducción del déficit público que habían motivado su reclutamiento dos años atrás.

\section{PREGUNTAS DE INVESTIGACIÓN, HIPÓTESIS Y METODOLOGÍA}

Los análisis llevados a cabo por Burch y Holliday y Tiernan evidencian que las estrategias de autorreforzamiento emprendidas por Blair y Howard mediante la reforma de sus respectivas estructuras de asesoramiento y apoyo produjeron efectos diferentes en lo tocante a la influencia del ministro de Economía. Así, mientras el canciller británico Gordon Brown vio mejorada su posición gracias a la creación de órganos e instrumentos que le dotaban de nuevas potestades (Burch y Holliday, 2004: 6), el titular del Tesoro australiano no quedó exceptuado en su gestión por el estilo de gobierno de Howard, que a menudo intervenía personalmente (asistido por su Prime Ministerial Office) en el ámbito de competencia de sus ministros cuando se trataba de asuntos significativos o sensibles (Tiernan, 2006: 316-317). Semejante disparidad en los resultados generados por procesos de naturaleza similar, lejos de agotar los incentivos para seguir indagando en los mismos, constituye una sugestiva invitación a buscar nuevas respuestas a tres grandes preguntas relacionadas entre sí: ¿̨por qué un jefe de Gobierno decide emprender una reforma institucional destinada a incrementar su capacidad de influencia? ¿Cómo implementa esta estrategia de autorreforzamiento? ¿Qué impacto produce dicha estrategia en la influencia de otros actores involucrados en la actividad del Gobierno como el ministro de Economía?

Dados estos interrogantes, aquí se plantea una investigación llamada a proveer evidencias que sustenten las observaciones realizadas recientemente por varios estudiosos del centro presidencial español sobre las relaciones conflictivas establecidas en los últimos tiempos entre los asesores del jefe de Gobierno y el ministro de Economía, especialmente durante la presidencia de José Luis Rodríguez Zapatero. A tal fin, las preguntas que se derivan del examen de la literatura comparada se reformularán para adaptarlas a las particularidades del caso escogido, articulándose del siguiente modo: ¿por qué decidió el presidente Zapatero crear la OEP? ¿Cómo convirtió a la OEP en un órgano involucrado en la toma de decisiones? ¿En qué medida se vio negativamente afectada la influencia del ministro de Economía por el activismo de la OEP? La hipótesis que guiará nuestra búsqueda de respuestas es que el presidente Zapatero creó un órgano de asesoramiento presidencial en materia económica, la OEP, para incrementar su capacidad de influencia. A tal fin 
proveyó a la misma de una serie de recursos (políticos, legales, presupuestarios y de personal) que la convirtieron en un actor relevante en el funcionamiento del core executive. Dicha estrategia de autorreforzamiento acabó afectando negativamente a Pedro Solbes, ministro de Economía y Hacienda entre 2004 y 2008, en la medida que vio restringida su autonomía en el proceso de toma de decisiones gubernamental.

La reforma del centro presidencial, según se infiere de procesos sometidos a estudio en el ámbito internacional, adopta expresiones diversas y tiene efectos asimismo disímiles, pero invariablemente redunda en un aumento de las capacidades del jefe de Gobierno. En el caso que nos ocupa, dicho proceso de reforma habría sido problemático, aparentemente, en la medida que se dotó al órgano de asesoramiento económico del presidente de potestad para involucrarse activamente en procesos de toma de decisiones correspondientes al ámbito del Tesoro. Lejos de representar una anomalía, la posibilidad de que la OEP actuara como una instancia emisora de iniciativas políticas, trascendiendo así su dimensión estrictamente consultiva, encuentra respaldo en la literatura. Así, por ejemplo, en el curso de una investigación encabezada por Blondel y Müller-Rommel sobre el funcionamiento interno de los Gobiernos, no pocos de los ministros y exministros entrevistados reconocieron al prime ministerial staff (del que la OEP sería una parte) un rol político (consistente no solo en el asesoramiento personal al primer ministro, sino también en la formulación de alternativas políticas) más allá de un rol administrativo (basado en la preparación de la agenda del Gabinete y/o el control de las propuestas de los ministros) que se percibe como natural (Blondel y Müller-Rommel, 1993: 136-137).

Por otro lado, esta idea es consistente con lo observado hace casi treinta años por Ortega respecto al Gabinete del presidente, al que reconocía capacidad para sugerir al premier una posición política distinta de la formulada desde un ministerio cualquiera (Ortega, 1991: 238). Si además tenemos en cuenta que el tipo de relación establecida entre el presidente y el titular de Economía se ve decisivamente afectada por el grado de especialización de sus respectivas estructuras de apoyo (Larsson, 1993: 211), o que — según se ha comprobado para el caso argentino- el presidente puede plantear diseńos institucionales de naturaleza competitiva entre sus asesores económicos y el ministerio del ramo, aunque termine respaldando al segundo (Bonvecchi, 2018), las preguntas de investigación arriba formuladas sugieren un esquema interpretativo alineado con los hallazgos realizados por las contados trabajos centrados en este aspecto particular del Gobierno. En este sentido, también en sintonía con uno de los trabajos más recientes sobre los órganos de asesoría presidencial en España, aquí se asume que la OEP equivale a uno de los procedimientos ex post definidos desde el institucionalismo (y más específicamente 
desde la teoría delegación): que el principal (el presidente) promueve para evitar, en la medida de lo posible, pérdidas de agencia (Garrido y Martínez, 2018: 167-168).

Para obtener evidencias que nos permitan responder a los interrogantes formulados y lograr los objetivos propuestos, se ha desplegado una metodología que combina el análisis documental de fuentes primarias (legislación, noticias de prensa, programas electorales, etc.) y secundarias (trabajos periodísticos sobre el Gobierno de Zapatero) con la realización de entrevistas semiestructuradas a personas que aportaron información relevante sobre las dinámicas estudiadas, ya sea en calidad de participantes directos o como observadores cualificados 5 .

\section{CREACIÓN Y EVOLUCIÓN DE LA OFICINA ECONÓMICA DEL PRESIDENTE EN EL PRIMER GOBIERNO DE ZAPATERO (2004-2008)}

Para comprender cómo se crea la OEP hay que remontarse a Economistas 2004, una experiencia previa que tuvo lugar durante el segundo Gobierno de José María Aznar. Y para entender las razones que conducen a la constitución de Economistas 2004 hay que situarse en el contexto de la legislatura 2000-2004. Esta se había iniciado con la consecución de una mayoría absoluta por parte del PP en las elecciones generales, un hecho inédito para la joven democracia española, que durante casi catorce años de su existencia (1982-1996) había tenido al PSOE como partido gubernamental. Con este contundente resultado electoral, la sociedad había premiado a los populares por su primera actuación al frente del Gobierno de la nación, marcada por los éxitos económicos y la moderación política (Santamaría, 2007: 35). El fracaso cosechado por los socialistas en las urnas, lejos de esa dulce derrota que cuatro años atrás les había llevado a la oposición tras más de una década de hegemonía, indujo un proceso de renovación interna que

5 Las personas entrevistadas fueron, por orden alfabético, Francisco Javier García Fernández (secretario general técnico del Ministerio de Vivienda entre 2004 y 2007), Enrique Guerrero Salom (subdirector de Gabinete de Presidencia entre 2004 y 2008), José María de Luxán Meléndez (director del Gabinete del Secretario de Estado de Universidades e Investigación entre 2006 y 2008), Gustavo Nombela Merchán (subdirector general de Desarrollo Sostenible en la Oficina Económica del Presidente entre 2004 y 2007), Pedro Sánchez Pérez-Castejón (miembro del PSOE participante en Economistas 2004), y Miguel Sebastián Gascón (director de la Oficina Económica del Presidente entre 2004 y 2006). 
culminó con la elección de José Luis Rodríguez Zapatero como secretario general del PSOE en el XXXV Congreso celebrado por esta formación en julio de 2000 (Verge, 2007: 54-55).

Superada la crisis interna desatada por el fiasco electoral, los socialistas se reengancharon a la legislatura que llevaba varios meses en marcha con nuevo líder y nuevo equipo dirigente. Uno de los principales retos a los que se enfrentaba el renovado PSOE era el de articular una alternativa atractiva y creíble en materia de política económica, algo que se antojaba harto difícil en consideración del buen comportamiento que rendían los indicadores económicos más apreciados por la población: desempleo, crecimiento e inflación. A tal efecto, el diputado socialista Jordi Sevilla, responsable del partido en el área de Economía, organizaba con cierta regularidad unas reuniones a las que eran convocados economistas simpatizantes del PSOE — entre los que se contaban exministros de la era de Felipe González como Carlos Solchaga, Javier Gómez Navarro o Juan Manuel Eguiagaray, o personalidades procedentes del mundo académico como el catedrático Emilio Ontiveros (Aizpeolea, 2004: 65; Jaén y Escudier, 2007: 174; García Abad, 2010: 235-238).

En una de estas reuniones Zapatero conoció a Miguel Sebastián, economista responsable del Servicio de Estudios del BBVA. La sintonía personal entre ambos fue inmediata. De entrada, al secretario general del PSOE le merecía reconocimiento el hecho de que Sebastián, proviniendo de la banca, se hubiera pronunciado favorablemente respecto al tipo único en el impuesto sobre la renta de las personas físicas (IRPF), una de las propuestas económicas formuladas por Jordi Sevilla — profesión de simpatía hacia el primer partido de la oposición que, según ciertos testimonios, le costó a Sebastián su puesto en aquella entidad bancaria- ${ }^{6}$. Pero, a decir de varios observadores, los factores realmente decisivos para que Sebastián adquiriera una posición prominente en el entorno de Zapatero fueron, por un lado, su discurso crítico con la visión complaciente que reinaba entre los socialistas en relación con la situación económica (que a la postre equivalía a una bendición de la política económica llevada a cabo por los Gobiernos del PP) y, por otro lado, su capacidad para hablar de asuntos económicos de una manera fresca, didáctica y muy persuasiva (Aizpeolea, 2004: 203; Jaén y Escudier, 2007: 111-112; García Abad, 2010: 235-240).

6 Este desenlace tendría su origen en el malestar que produjeron las manifestaciones de Sebastián en Rodrigo Rato, entonces vicepresidente económico, pues Francisco González, presidente del BBVA y amigo del segundo, no habría tenido problema alguno en prescindir de los servicios del díscolo economista para preservar sus buenas relaciones con el dirigente popular (Estefanía, 2007: 40-41; Jaén y Escudier, 2007: 114). 
Sea como fuere, lo cierto es que acabó atribuyéndose a Sebastián la responsabilidad de coordinar la elaboración de la parte económica del programa electoral. Tal decisión fue favorecida por una idea de Alfredo Pérez Rubalcaba, la de «vender a la sociedad» que las mentes económicas de mayor prestigio estaban trabajando para el PSOE, una operación publicitaria que el exministro socialista juzgaba como muy necesaria en la medida que la economía era uno de los puntos fuertes del Gobierno popular. Esta atmósfera propició el aterrizaje en Ferraz de Miguel Sebastián, cuyo nombre ya había sido sugerido por el exgobernador del Banco de España, Luis Ángel Rojo, después de que el candidato socialista consultara a su antecesor Felipe González acerca de personas merecedoras de crédito en el terreno económico. Una vez producido el flechazo entre Zapatero y Sebastián, y en el marco de esa estrategia de marketing concebida por Rubalcaba, la adjudicación al recién llegado de la coordinación del programa económico se visualizó con el lanzamiento de la plataforma Economistas 2004 (Estefanía, 2007: 41; Jaén y Escudier, 2007: 113-114).

\section{ECONOMISTAS 2004: LA GALAXIA PARTICULAR DE MIGUEL SEBASTIÁN EN EL UNIVERSO DE LA OPOSICIÓN SOCIALISTA AL EJECUTIVO DE AZNAR}

Economistas 2004 se ha descrito como «un grupito privado de economistas» al que se integraron "expertos que no eran del partido", como un búnker desde el cual Sebastián se dedicaba "prioritariamente a lanzar mensajes a los medios de difusión en la línea crítica que expuso a Zapatero en su primera entrevista» (García Abad, 2010: 238-239). También se ha dicho que Sebastián se limitó a asumir la dirección de los grupos de discusión económica que ya estaban funcionando con Sevilla y, «sin aportar grandes ideas, reinventó el discurso, lo envolvió en celofán de colores y se lo vendió a Zapatero" (Jaén y Escudier, 2007: 114-115). Empero, a la luz de los testimonios ofrecidos por el propio Miguel Sebastián y Pedro Sánchez (uno de los principales participantes en Economistas 2004) tales afirmaciones merecen ser matizadas, ampliadas o directamente refutadas.

Así, por ejemplo, en lo relativo a las funciones desarrolladas por Economistas 2004, la versión ofrecida por Sebastián y Sánchez plantea un escenario bastante más complejo del que cabría esperar de una mera operación de marketing o de una plataforma dedicada fundamentalmente a una política de comunicación de tipo sectorial. A este respecto, más allá de elaborar el programa económico (que era su principal cometido), el grupo liderado por Sebastián estaba llamado a desempeñar tres misiones, según cabe desprender del testimonio de Sánchez. En primer lugar, «que todas las propuestas [...] 
estuvieran tasadas desde el punto de vista económico», una inquietud que provenía del propio Zapatero, "obsesionado" con legitimar presupuestariamente unos proyectos y reformas que en el Congreso de los Diputados recababan sistemáticamente de «Montoro, Rato, Aznar» la pregunta de «iesto [...] cuánto va a costar?». En segundo lugar, es cierto que se atribuyó a Economistas 2004 la tarea de difundir el diagnóstico de la situación y las correspondientes alternativas políticas, que comprendían la visión económica de la opción representada por Zapatero. No obstante, dicha encomienda no se traducía únicamente en la publicación de "artículos en medios de comunicación», sino que también se intentaba «estar presentes en muchos foros donde se debatía sobre economía para que se viera que [...] había gente de la profesión, vinculada desde un punto de vista progresista al PSOE, que tenía muchas cosas que decir sobre una economía que entonces parecía que iba muy bien pero que tenía problemas».

En tercer lugar, recuerda Sánchez que Economistas 2004 acabó siendo también una cantera de altos cargos del área económica en los Gobiernos de Zapatero. Prueba de ello son los nombres de David Vegara (secretario de Estado de Economía hasta la salida de Solbes, ${ }^{7}$, Soledad Núñez (directora del Departamento de Política Económica de la OEP desde 2004 a 2005, y posteriormente directora general del Tesoro hasta 2011) ${ }^{8}$, Javier Vallés (esposo de su predecesora al frente del Departamento de Política Económica, y luego director de la OEP durante la segunda legislatura de Zapatero) ${ }^{9}$, Maurici Lucena (director general del Centro para el Desarrollo Tecnológico Industrial entre 2004 y 2010 ${ }^{10}$, o Julio Segura (presidente de la Comisión Nacional del Mercado de Valores entre 2007 y 2012 ${ }^{11}$.

En todo caso, más allá de sus funciones de altavoz mediático y cantera de mandarines, quizá lo más importante sea subrayar que Economistas 2004 no fue una simulación de mecanismo participativo para la elaboración de una parte del programa electoral ni una experiencia de la que Zapatero estuviera absolutamente al margen (como asimismo cabría inferir de las informaciones

7 «El español David Vegara, nombrado número dos del fondo de rescate europeo». El País, 19-09-2012. Disponible en: https://bit.ly/2Thc45G.

8 Domínguez, M. (2012). «Perfil de Soledad Núñez: diligente e infatigable». Eleconomista.es, 08-06-2012. Disponible en: https://bit.ly/2T9AsX3.

9 "Javier Vallés, nuevo director de la Oficina Económica de Moncloa». Eleconomista.es, 18-04-2008. Disponible en: https://bit.ly/3Acie7V.

10 «Maurici Lucena deja la dirección del CDTI». El País, 14-05-2010. Disponible en: https://bit.ly/3x8A1Lk.

11 "La diputada del PP Elvira Rodríguez, nueva presidenta de la CNMV». El País, 20-092012. Disponible en: https://bit.ly/2Sys6rp. 
periodísticas referidas más arriba). De lo primero no solo da buena cuenta el número de personas involucradas o la metodología de trabajo, sino también la circunstancia de que hubo debates muy encendidos, como por ejemplo con el tema de la política laboral, reconocen tanto Sebastián como Sánchez. Tal cosa vino en parte propiciada por el hábito de celebrar encuentros entre integrantes de Economistas 2004 y grupos de trabajo responsables de otras áreas del programa electoral (como sanidad o política social) una vez que estos tenían cerradas sus propuestas, al objeto de "cotejar su viabilidad económica» y en general someter a examen su "concordancia con otras partes del programa electoral», asiente Sánchez — costumbre que, según Sebastián, les dotó de «mucho poder»asistió a "dos o tres debates», rememora Sánchez, entre ellos el de la reforma fiscal y el de la reforma del sistema energético, que este entrevistado identifica como cuestiones a las que el candidato socialista concedía especial importancia.

\section{DE LA OPOSICIÓN AL GOBIERNO: UN TRAYECTO MINADO DE CONDICIONANTES}

Habida cuenta del protagonismo de Sebastián en la definición del programa económico, no ha de resultar extraño que Zapatero mantuviera su compromiso con él una vez conocidos los resultados electorales y le ofreciera no solo la cartera de Economía, sino también una vicepresidencia económica. El principal argumento esgrimido por el presidente in pectore fue que necesitaba dejar la economía en sus manos, pues entendía que habría de volcar sus esfuerzos como líder del Ejecutivo en las políticas antiterrorista, exterior y territorial. Según cuenta Sebastián, en el pasado ya le había dicho a Zapatero que solo le acompañaría hasta marzo de 2004, y aunque se tomó un par de días para meditar su respuesta, el economista perseveró en su negativa a entrar en el Consejo de Ministros, pues no se sentía preparado para tamaña responsabilidad (Aizpeolea, 2004: 65; García Abad, 2010: 241-242).

Seguramente, el retraimiento voluntario de Sebastián fue acogido con satisfacción en ciertos sectores del PSOE, que no sentían hacia el responsable del programa económico la misma admiración que le dispensaba Zapatero. Por otro lado, una vez descartado Sebastián, el nombre de Pedro Solbes parecía concitar un amplio y rápido consenso entre personalidades de referencia en el partido como el expresidente Felipe González, y varios ex altos cargos del área económica de la primera etapa socialista como Carlos Solchaga, Miguel Ángel Fernández Ordóñez, Javier Gómez Navarro y el que fuera gobernador del Banco de España, Luis Ángel Rojo — de hecho, es posible que el propio Sebastián sugiriera al líder socialista que adjudicara el departamento de Economía 
a quien entonces encabezaba dicho ramo en la Comisión Europea-. Rojo convenció a Zapatero de que, como responsable de las cuentas públicas, Solbes podría "frenar a los ministros impulsivos" en lo tocante al gasto (Aizpeolea, 2004: 65). Gómez Navarro le reiteró al todavía presidente virtual una idea que ya le había transmitido con anterioridad: "iPara qué hace falta estar explicando a los empresarios qué política económica vais a hacer? ¡Traed a Solbes y lo entenderán enseguida!» (Jaén y Escudier, 2007: 162-163).

En conclusión, la necesidad de tranquilizar al mundo económico en un contexto marcado por la inesperada victoria electoral de un partido que traía propuestas de reforma de cierta audacia (singularmente en el plano fiscal), así como la perspectiva de que los ministros iban a ejercer una especial presión hacia el gasto, dada la coyuntura de bonanza económica y el estado saneado de las arcas públicas, recomendaban la elección como responsable de Economía y Hacienda de alguien cuyo nombramiento era en sí mismo «un proyecto de credibilidad» - a decir de Enrique Guerrero, que trabajó para Zapatero en Moncloa-. Es probable que por estos mismos motivos Sebastián no fuera percibido como una solución de garantía (ni siquiera por él mismo), pues si bien su prestigio académico e intelectual estaba fuera de toda duda, carecía de la auctoritas política necesaria para inspirar confianza en los mercados y disciplinar a unos ministros presumiblemente ávidos de recursos para impulsar las políticas prometidas en campaña. Este capital político, que probablemente solo da la experiencia en el desempeño de máximas responsabilidades, estaba más que acreditado en el caso de Pedro Solbes, que además de comisario europeo había sido ministro de Economía y Hacienda con Felipe González entre 1993 y 1996, después de haberse fogueado como ministro de Agricultura (1991-1993) y secretario de Estado para las Comunidades Europeas (1985-1991).

No obstante, la fallida promoción ministerial de Miguel Sebastián no equivalía en modo alguno a su relegación del organigrama gubernamental. Este se veía a sí mismo asesorando personalmente a Zapatero, como había venido haciendo hasta los comicios, y todo apunta a que el líder de los socialistas quería seguir teniendo cerca a su gurú económico. En este punto se produce una primera fricción en el incipiente entorno presidencial, pues José Enrique Serrano (veterano fontanero socialista destinado a asumir la jefatura del Gabinete de Presidencia, un cargo que ya había desempeñado con Felipe González) se resiste a que Sebastián tenga rango de secretario de Estado, tal y como él desea. Sebastián justifica su demanda con el argumento de que quiere tratar directamente con Zapatero sin la intermediación de Serrano, y este sostiene que un Gabinete de Presidencia ha de estar articulado a través de una jerarquía clara, sin bicefalias. Sebastián opina, sin embargo, que de haber una vicepresidencia política y otra económica resulta lógico que tal esquema se 
reproduzca en la estructura de apoyo al premier. Por otro lado, más allá de las razones de índole organizativa, el responsable de la parte económica del programa electoral no oculta su pretensión de participar en la Comisión Delegada de Asuntos Económicos, instancia presidida por el vicepresidente económico en la que se prepara el apartado económico de los Consejos de Ministros ${ }^{12}$. A pesar de las reticencias de Serrano, que trató de apoyarse en la vicepresidenta primera María Teresa Fernández de la Vega para neutralizar a Sebastián, este consiguió su propósito (Aizpeolea, 2004: 80-81).

\section{LA OFICINA ECONÓMICA DEL PRESIDENTE SE PONE EN MARCHA}

Aunque el final de Barea y su Oficina del Presupuesto no permitía realizar augurios optimistas sobre la constitución de instancias específicas para el asesoramiento presidencial en materia económica al margen de la estructura del Gabinete, Sebastián no se conformó con el rango de secretario de Estado y decidió dar vida a un espacio institucional propio: la Oficina Económica del Presidente. Si la Oficina del Presupuesto de Barea estaba inspirada en el órgano del mismo nombre sito en la Casa Blanca ${ }^{13}$, el modelo que seguir para el gurú económico de Zapatero también estaba en los Estados Unidos, pero no era el mismo que había servido de referencia al zar antidéficit de José María Aznar. En este sentido, afirma Sebastián que su idea era erigir en Moncloa una suerte de Council of Economic Advisers, tal y como existe en la Administración presidencial estadounidense. Otro de los entrevistados, Gustavo Nombela, aludió asimismo a este órgano a la hora de enumerar experiencias pasadas o contemporáneas que ejemplificaban lo que el personal de la OEP pretendía hacer de este departamento.

El Council of Economic Advisers, creado en 1946 por el Employment Act, está integrado por tres miembros elegidos por el presidente (uno de los cuales ejerce como chair), y tiene como misiones principales asistir al jefe de Estado estadounidense con el asesoramiento en asuntos económicos, y la preparación de estudios de prospectiva (Genovese, 2004: 120). La segunda de las funciones se antoja importante para comprender el nacimiento de la OEP, pues a juicio de Sebastián «hacía falta un sitio que mirara más el largo plazo»,

12 Esta cuestión está relacionada con la disputa por el rango de secretario de Estado, pues según lo dispuesto por el art. 6 de la Ley 50/1997 del Gobierno (LG), relativo a las comisiones delegadas del Gobierno, estas habrán de estar integradas por miembros del Gobierno y, en su caso, secretarios de Estado.

13 Franco Oliván, J. A. (1996). «Barea: “José María Aznar quiere lucha contra el déficit a toda costa"». $A B C, 08-05-1996$. 
que «habla[ra] de las tendencias y se aleja[ra] del día a día». Semejante necesidad ya habría sido detectada por Sebastián tras su paso por el Ministerio de Economía en la era Solchaga ${ }^{14}$, cuando comprobó que el trabajo realizado en materia de prospectiva era paulatinamente desplazado hasta quedar en nada, en beneficio de la actividad requerida por la satisfacción de urgencias a corto plazo, y a causa de la escasez de recursos a disposición del Tesoro. En todo caso, al margen de los argumentos políticos invocados entonces y ahora para justificar la creación de la OEP, la secuencia de los hechos pone de manifiesto que esta reforma concreta del centro presidencial estuvo inspirada por el fenómeno de la personalización, apreciado en procesos análogos citados más arriba.

A tenor del Real Decreto 1689/2004, por el cual se desarrollaba la estructura orgánica de la Presidencia del Gobierno, la OEP se organizó formalmente mediante una estructura encabezada por el director, del que dependían tres unidades orgánicas (una subdirección, un Departamento de Política Económica y otro de Sociedad del Bienestar) cuyos titulares disfrutaban de rango de director general (art. 11 RD 1689/2004). El Departamento de Política Económica tenía encomendada la realización de estudios e informes sobre las políticas fiscal, presupuestaria, financiera y de empleo, así como acerca de las relativas a las relaciones económicas internacionales (art. 14 RD 1689/2004), mientras que el de Sociedad de Bienestar habría de hacer lo propio respecto a las políticas de índole social, sectorial y territorial, incluidas también las relativas al desarrollo sostenible (art. 14 RD 1689/2004). Esta ordenación formal de atribuciones encubría, empero, la distribución de competencias que de facto regía el funcionamiento de la OEP. Así, tanto Sebastián como Nombela coinciden en señalar que el departamento encabezado por Núńez se ocupaba en realidad de acometer análisis macroeconómicos, mientras que el comandado por Marín se ocupaba del enfoque microeconómico. Respecto al Departamento de Sociedad del Bienestar, Nombela especifica además que se encargaba de los temas que entraban en el ámbito de los ministerios de Medio Ambiente, Fomento, Vivienda, Sanidad y Educación.

Si las etiquetas de los departamentos no expresaban de manera exacta el contenido temático de los trabajos desarrollados por sus respectivos integrantes, de igual modo cabe decir que la verticalidad del organigrama plasmado en el RD 1689/2004 no tenía su correlato en una jerarquía estricta dentro de la OEP. Tal cosa venía dada por el hecho de que una parte importante de su actividad consistía en la preparación de informes para el director

14 Sánchez, A. I. (2009). «Economistas de cabecera». ABC, 12-04-2009. Disponible en: https://bit.ly/3jpop2d. 
sobre los asuntos que iban a ser abordados en la Comisión Delegada de Asuntos Económicos, y a partir de las memorias económicas de los proyectos ministeriales. En este sentido, asegura Nombela, eran de alguna manera los ministerios los que marcaban la agenda de sus estudios e investigaciones, sin que existieran ciertas pautas o directrices por parte de alguno de los responsables directivos. Por otro lado, todo parece indicar que Sebastián quiso imprimir a la OEP la dinámica propia de un departamento universitario o, en todo caso, promover un ambiente que nada tuviera que ver con las rigideces jerárquicas que conoció en sus cinco años en el Banco de España (lo peor que le puede pasar a un think-tank, a juicio de quien fuera director entre $2004 \mathrm{y}$ 2006). Prueba de este espíritu, evoca Nombela, serían los seminarios de tipo académico, que en una primera época organizaba Sebastián para discutir sobre un tema previamente expuesto por un especialista externo.

En lo relativo a los medios que se pusieron a disposición de la OEP, Sebastián insiste en que esta «se crea sobre recursos que ya existían». Este extremo resulta difícil de comprobar, en primer lugar por la inaccesibilidad de los datos que permitirían verificar tal aserto. Por otro lado, no pocas de las informaciones periodísticas que abordaron esta cuestión lo hicieron de una manera sensacionalista y tendenciosa, comparando, por ejemplo, el número de personas empleadas en la Oficina del Presupuesto de Barea con el montante de individuos integrantes de la OEP, sin tener en cuenta que la primera coexistió con un Departamento de Economía del Gabinete de Presidencia ${ }^{15}$. No obstante, incluso dando por válida la información publicada en este y otros artículos (pues se remitían a la web que entonces tenía la OEP, así como a una respuesta ofrecida en el Parlamento a este respecto), el órgano encabezado sucesivamente por Sebastián y David Taguas habría llegado a estar compuesto por una cuarentena de personas ${ }^{16}$, de los cuales veintisiete eran economistas (un secretario de Estado, tres directores generales, nueve «niveles $28 »$ y catorce «niveles $30 »)^{17}$.

En este sentido, es seguramente cierto que la OEP no requirió más personal administrativo del que ya estaba adscrito al Departamento de Economía del Gabinete de Presidencia (esa decena larga de individuos que resulta de restar a cuarenta los mencionados veintisiete economistas). De

15 Véase nota 3.

16 Kölling también habla de un total de cuarenta personas integrando la OEP entre funcionarios, académicos e individuos procedentes del sector privado (Kölling, 2009: 142).

17 «La oficina de los “líos” se halla en La Moncloa». El Mundo, 13-05-2007. Disponible en: https://bit.ly/3qAeKHR. 
hecho, en la información aquí utilizada se dice que no estaban cubiertas más de veinte plazas de todas las recogidas en la relación de puestos de trabajo de la OEP. Sin embargo, el reclutamiento de casi treinta economistas apunta a un crecimiento inusitado, aunque sectorialmente localizado, de la estructura de asesoramiento y apoyo del presidente del Gobierno. Así, aunque falten datos precisos que nos permitan construir una serie histórica completa, el hecho de que - por ejemplo - el Departamento de Economía del Gabinete presidencial de Felipe González acogiera, hasta 1994, a no más de ocho personas dedicadas propiamente a tareas de asesoramiento (Olías, 1994: 269), invita a pensar en la OEP como un punto de inflexión en la evolución del tamaño del prime ministerial staff en España, en línea con lo ocurrido en procesos homologables de reforma del core executive citados anteriormente.

\section{A MEDIO CAMINO ENTRE UN THINK-TANK Y UNA VENTANILLA PARA EL MUNDO DE LAS GRANDES EMPRESAS}

La puesta en marcha de la OEP generó suspicacias en prácticamente todos los actores involucrados en el Gobierno, ya se tratara de los ministerios o de otras estructuras de asesoramiento y apoyo al presidente. Sebastián lo explica recurriendo a una metáfora inspirada en la biología: "Éramos un cuerpo nuevo, extrańo [...] un cuerpo extraño genera inmediatamente todos los anticuerpos para matarlo, eso nosotros lo notamos desde el primer día». En esta misma línea Nombela señala que al ser un nuevo actor y estando los ministerios "habituados a sus rutinas", al principio estos mostraron ciertas reticencias a proporcionar la información que se les requería desde la OEP, percibida por los distintos departamentos como un grupo de «supervisores» enviados por el presidente para fiscalizar la actividad ministerial. No obstante, puntualiza que «en general, enseguida la Oficina se integró muy bien en la estructura administrativa», de tal suerte que al final se veía a la OEP como una fuente de colaboración y asesoramiento. Sebastián coincide con esta visión, y lo achaca al hecho de que la OEP aligeraba la carga de trabajo de los ministerios a solicitud de estos, es decir, terminaron siendo «la Oficina Económica de todo el Gobierno».

Sin embargo, el encaje de la OEP en el Gobierno no constituyó un proceso completo ni totalmente satisfactorio, pues a juicio de Sebastián fue constante la animosidad dispensada a esta instancia desde el Gabinete de Presidencia y el Ministerio de Economía y Hacienda ${ }^{18}$. A quien fuera primer

18 Sebastián admite, no obstante, que en un primer momento Solbes se mostró «extremadamente amigable con la Oficina Económica», llegando a manifestar que iba 
director de la OEP, el «enconamiento» del Fisco le parece algo «lógico», habida cuenta de que el nuevo órgano ciertamente invadía "parte de su terreno». Por otro lado, afirma Sebastián que la rivalidad entre el ministerio de Economía y la OEP encuentra su paralelo en los EE. UU., concretamente en las tradicionalmente tensas relaciones entre el Tesoro y el Council of Economic Advisors, eventualidad de la que advirtió a Sebastián el economista Martin Feldstein, presidente de este cuerpo durante la Administración de Ronald Reagan. Empero, la hostilidad del Gabinete de Presidencia, coherente con las resistencias de su director José Enrique Serrano a que Sebastián tuviera rango de secretario de Estado, habría venido dada por la hegemonía en su seno de la «vieja guardia» socialista, que «desde el primer día» no dejó «ni respirar» a Sebastián y los suyos, en la premisa de que el director de la OEP, con otras personas del entorno de Zapatero que tampoco tenían el carné del PSOE, representaba una amenaza para las «esencias del partido».

Esta parte del relato de Sebastián resulta consistente con los juicios negativos que - de manera explícita o indirecta - le dispensan al exdirector de la OEP algunos de los entrevistados para este trabajo, cuyas carreras políticas se remontan a la época de Felipe González. De hecho, uno de ellos, ex alto cargo en el Gobierno socialista del lapso 2004-2008, opina que Sebastián es uno de los tres factores explicativos de la mala fortuna política de Zapatero (junto al «optimismo antropológico» del otrora líder socialista y la crisis económica), pues el primero habría sido responsable de confundir continuamente al segundo. Este mismo entrevistado rechaza igualmente la consideración de la OEP como un think-tank, ya que este órgano habría sido, por un lado, una instancia dedicada a tareas rutinarias de análisis que no requerían contribuciones personales desde el punto de vista argumental, como por ejemplo la actualización y síntesis para el presidente de estudios de coyuntura elaborados por entidades nacionales o internacionales, o la preparación de borradores de discursos presidenciales para foros económicos.

En todo caso, concede este entrevistado, la OEP llevaba a cabo evaluaciones de las propuestas de los ministerios (analizando "problemas que podría suscitar, problemas que resuelve»), pero siempre desde una perspectiva academicista, idealista, ajena a la realidad de los sectores afectados, un enfoque que a juicio de quien fuera mandarín de Moncloa contrastaría con el practicado

a dotarla de «todos los recursos» que le pidieran. Aún admitiendo que las diferencias surgieron tempranamente, Solbes explica en sus memorias que apoyó la creación de la OEP desde el primer momento, en la premisa de que el presidente debía participar en el proceso de toma de decisiones relativo a la política económica con el mismo tipo de asistencia técnica ya disfrutada por sus homólogos europeos. Además, pensaba que la colaboración de Sebastián podía ser «enormemente útil» (Solbes, 2013: 273). 
desde los ministerios, donde en términos generales la legislación se prepara en interlocución con todos los agentes implicados. Por otro lado, esta persona sostiene que la OEP habría sido la plataforma del presidente para las relaciones con las empresas y, más concretamente, el cuartel general donde se gestaron operaciones relacionadas con el capital participante en determinadas grandes corporaciones o con el intento de recambio de sus máximos dirigentes.

Esta visión, a pesar de su tono crítico, es parcialmente compatible con el relato de Sebastián y Nombela, quienes admiten que en efecto la OEP acabó siendo víctima del trabajo rutinario motivado por las exigencias inmediatas, en detrimento de ese pensamiento a largo plazo que se quería promover en un primer momento. Sin embargo, el veterano socialista arriba citado obvia una faceta de la OEP que habla inequívocamente de su dimensión de think-tank: la derivada del protagonismo ganado por este órgano en el desarrollo de la política europea de España con el nombramiento en 2005 de su director Miguel Sebastián como coordinador del Gobierno espańol para la Estrategia de Lisboa y responsable del Programa Nacional de Reformas (PNR) (Kölling, 2009: 142). Por su propia naturaleza, esta encomienda hubo de traducirse necesariamente en una actividad orientada a la formulación y proyección de políticas públicas, independientemente de que otras tareas menos creativas detrajeran una parte importante de tiempo a los economistas de la $\mathrm{OEP}^{19}$. En este sentido, Nombela identifica el Plan Ingenio — relativo a la estrategia de $\mathrm{I}+\mathrm{D}+\mathrm{i}^{20}$ - como un producto genuino de la OEP, si bien a este respecto es preciso hacer otra puntualización que matiza el juicio del ex alto cargo de Moncloa expuesto anteriormente.

$\mathrm{Y}$ es que si algunas iniciativas pudieron llevar el sello de la OEP (por haber sido originariamente concebidas en su seno), esta instancia no era la única responsable de su elaboración ni desarrollaba su actividad en un clima de aislamiento o enajenación. Tal cosa no podía ser así, en primer lugar, porque los trabajos relacionados con el PNR se organizaron en torno a la Unidad Permanente de Lisboa (UPL), un órgano que, aun reconociendo el

19 A este respecto, Nombela reconoce, por ejemplo, que tenían «momentos de mucho trabajo, muy puntual [...] en puntos clave de la legislatura, [como por ejemplo] en los debates sobre el estado de la Nación [...]. Ahí la Oficina participaba mucho haciendo el trabajo previo, digamos revisión de temas, preparación de notas y de fichas para el presidente».

20 En estos años la estrategia $\mathrm{I}+\mathrm{D}+\mathrm{i}$ formaba parte de una política más ambiciosa, orientada a la atracción de fondos europeos procedentes de fuentes diferentes a las tradicionales, pues con la ampliación de la UE a Europa del Este, Espańa se convertiría en un contribuyente neto tras décadas siendo un Estado receptor (Closa, 2009). 
liderazgo a la OEP, reunía a esta y a los ministerios de Economía, Trabajo, Industria y Medio Ambiente (Mulas, 2007: 232). Pero, además, los entrevistados José María de Luxán y Nombela, que respectivamente personifican una perspectiva ministerial y otra de la OEP, concuerdan a la hora de señalar que el diálogo entre la Oficina y los demás departamentos del Gobierno era una constante, tanto en otros cauces de tipo oficial como en un nivel más informal.

Luxán cita como ejemplo la Comisión Interministerial de Ciencia y Tecnología (CICYT), cuya secretaría recayó sobre Pedro Marín (director del Departamento de Sociedad del Bienestar de la OEP), quien a su vez se ponía de acuerdo con el secretario de Estado de Universidades, Miguel Ángel Quintanilla, para decidir la convocatoria de las reuniones de esta instancia. Nombela, por su parte, recuerda que sus interlocutores habituales eran los jefes de gabinete de los ministros o los secretarios de Estado, con los que las relaciones fueron «muy fluidas» en la mayor parte de los casos, y añade más adelante que aquellos incluso solían solicitar la presencia de miembros de la OEP en reuniones «de discusión con los sectores» —algo que a juicio del entrevistado evidencia elocuentemente la rápida integración de los integrantes de la Oficina en la estructura ministerial—. Así pues, la crítica a la OEP por su desconexión de otros niveles de Gobierno o su desconocimiento de las inquietudes y necesidades de los actores económicos y sociales se antoja desprovista de fundamento no solo por lo dispuesto normativamente en lo tocante a la composición de comisiones interministeriales y otros órganos colegiados como la UPL, sino también por las prácticas informales referidas por personas directamente involucradas en los procesos de policy-making.

La apreciación de la OEP como una plataforma del presidente para relacionarse con el mundo empresarial merece, sin embargo, ser considerada como un juicio bastante aproximado a la realidad. En primer lugar, porque el propio RD 1689/2004 reconocía a la OEP un papel en la asistencia al presidente para su interlocución con el sector privado. Por otro lado, son varias las informaciones periodísticas que adjudican primero a Sebastián, y luego a Taguas, un relevante papel en el desarrollo de ciertas operaciones que tenían por protagonistas a grandes corporaciones bancarias, energéticas o de la construcción. Aunque su participación en estos episodios no ha sido confirmada por ninguno de ellos, cuando no ha habido directamente un desmentido se antoja indiscutible que tanto uno como otro conocían personalmente a prominentes figuras de las altas esferas económico-financieras - no en balde, ambos habían encabezado el Servicio de Estudios del BBVA antes de trabajar para el Gobierno-. Además, el propio Sebastián ha admitido, por ejemplo, que recomendó la permanencia del presidente de Repsol, Alfonso Cortina, a los dirigentes de La Caixa que promovieron su destitución, o que Luis del Rivero (presidente de la constructora Sacyr Vallehermoso) se dirigió primero 
a él en su particular operación de asalto a la presidencia del BBVA (García Abad, 2010: 212-216) ${ }^{21}$. Estos hechos son consistentes con la apreciación de que la OEP terminó siendo percibida por los ministerios y el mundo empresarial como una segunda instancia a la que acudir cuando las peticiones eran rechazadas por el Tesoro (Solbes, 2013: 274).

Así pues, la OEP habría sido como poco una ventanilla para el mundo de las grandes corporaciones, no solo por el hecho de que ciertos empresarios recurrieran a Sebastián o Taguas para tratar con ellos ciertas decisiones, sino porque consultar al sector privado y escuchar sus demandas entraba dentro de las funciones de este órgano en esquemas como el recomendado para la elaboración de los PNR (Mulas, 2007: 233). Pero incluso si Sebastián y Taguas hubiesen formado parte de manera deliberada de las estrategias empresariales de ciertas entidades, no hay que olvidar que esos mismos testimonios que les adjudican un rol protagonista también dan por bueno, por ejemplo, que Zapatero y su vicepresidente económico Pedro Solbes aspiraban a que las cúpulas de las empresas privatizadas por los Gobiernos del PP, encabezadas por personas afines a este partido, iniciaran un proceso de renovación tras la victoria electoral del PSOE que culminara con el nombramiento de presidentes de perfil independiente (Aizpeolea, 2004: 207-208; Jaén y Escudier, 2007: 220; García Abad, 2010: 211). En este sentido, si efectivamente hubiera existido una participación proactiva de los directores de la OEP en dinámicas del mundo empresarial, tal cosa no sería achacable a un activismo de raíz personal, sino más bien a ciertas ideas de la dirigencia socialista sobre el tipo de relación que quería establecerse entre la política y las grandes corporaciones.

Este punto de la reflexión nos lleva a la clave que rigió el funcionamiento y eficacia de la OEP, ya que las evidencias apuntan en su conjunto a que dicho órgano, tanto en su faceta de think-tank como en la de plataforma para las relaciones como los empresarios, actuó siempre al compás marcado por las inquietudes o aspiraciones del presidente Zapatero. Esto no quiere decir que las relaciones entre Zapatero y la OEP fueran unidireccionales, pero sí que el primero activaba a la segunda y tenía la última palabra en la toma de decisiones. La mutua retroalimentación entre el jefe de Gobierno y sus asesores económicos tuvo su reflejo en la política de $\mathrm{I}+\mathrm{D}+\mathrm{i}$, en la que la OEP resultó

21 Sebastián habría recomendado la permanencia de Cortina, a pesar de la afinidad de este con el PP, dada la enorme incertidumbre generada en las bolsas por los atentados del 11-M y el resultado electoral (García Abad, 2010: 212). En la operación de asalto al BBVA, por su parte, algunos han querido ver una vendetta personal de Sebastián contra el presidente de la entidad, Francisco González, que tiempo atrás le había despedido por sus simpatías con el PSOE (Jaén y Escudier, 2007: 221). 
crucial a la hora de orientar las preferencias del Ejecutivo hacia su incentivación (Kölling, 2009: 142), al igual que Zapatero se probó personalmente comprometido en la movilización de recursos para aquella partida — a decir de Luxán- . No obstante, el rol prominente de Zapatero respecto a la OEP quedó evidenciado de un modo especialmente elocuente en lo tocante a la política fiscal.

Esta última afirmación se justifica, en primer lugar, por el hecho de que la reforma fiscal diseñada bajo el liderazgo de Sebastián en el seno de Economistas 2004, plasmada en el programa electoral del PSOE («Merecemos una España mejor»), nunca llegó a materializarse a causa de la oposición del ministro Solbes ${ }^{22}$ — una postura que solo pudo estar bendecida por Zapatero- - . En segundo lugar, que la iniciativa pivotaba sobre el presidente - no solo por omisión, sino también por acción- se puso asimismo de relieve con la devolución universal de los 400 euros a través de una deducción en el IRPF, política atribuida por la prensa a una «Oficina Económica de Moncloa que todavía controlaba Miguel Sebastián a través de su amigo David Taguas» ${ }^{23}$ y que, sin embargo, constituyó una respuesta a cierta demanda de Zapatero, quien pidió a sus asesores propuestas de impacto para contrarrestar las medidas fiscales prometidas por el PP con vistas a los comicios generales de 2008 (García Abad, 2010: 202). El modus operandi que rigió este episodio, lejos de constituir una excepción, fue la tónica habitual en las relaciones entre Zapatero y el resto de actores que integraban su Gobierno, ya se tratara de la OEP o de los ministerios, a los que acudía a menudo en busca de ideas — singularmente de cara a los debates sobre el estado de la nación, puntualiza Nombela-.

Tras el episodio de los 400 euros y la reelección de Zapatero como presidente en 2008, la OEP experimentó un proceso de devaluación, pues el rango de su máximo responsable fue rebajado de secretario de Estado a director general, de tal suerte que aquella instancia quedaba fuera de la Comisión Delegada de Asuntos Económicos. Asimismo, se cesó a David Taguas, que venía desempeñando la dirección de la OEP desde diciembre de 2006 en una

22 La posición de Solbes en este asunto fue coherente con las políticas de ortodoxia fiscal iniciadas en el último Gobierno de Felipe González (1993-1996). Sin embargo, más que personificar una alternativa al paradigma dominante, Sebastián se contaba entre los economistas que defendían el abordaje de los problemas estructurales de la economía española (inflación diferencial, pérdida de competitividad y baja productividad) mediante inversiones adecuadas en infraestructuras y capital humano (Royo, 2009). Solbes, por su parte, estaba más preocupado con las reformas del mercado laboral y del sistema de pensiones (Solbes, 2013).

23 Sánchez, I. (2008). «Solbes, el ortodoxo, frena a los liberales del Gobierno». El Siglo de Europa, 8-09-2008. Disponible en: https://bit.ly/3qwFPvs. 
línea de continuismo respecto a la de su predecesor Sebastián, si bien es cierto que su mandato se caracterizó por iniciar la costumbre de publicar anualmente informes económicos del presidente, así como por cierta «deriva econométrica» (en palabras de Sebastián). Durante el segundo Gobierno de Zapatero, y con Javier Vallés al frente, la OEP mantuvo un perfil político y mediático bastante más bajo que en la legislatura anterior ${ }^{24}$. Esta situación se revirtió con la investidura de Mariano Rajoy como presidente, pues impulsó el relanzamiento de dicha instancia ${ }^{25}$, pero su remoción por Pedro Sánchez significó la desaparición definitiva de la misma ${ }^{26}$, configurándose desde entonces el asesoramiento económico en Moncloa a través de otras fórmulas organizativas ${ }^{27}$. Finalmente debe remarcarse que Solbes, al evocar sus años como ministro de Zapatero, se refiere en términos negativos a la OEP en mucha menor medida que a los sindicatos, las comunidades autónomas, otros colegas del Gabinete (singularmente Jesús Caldera, titular de Trabajo) y, sobre todo, el presidente Zapatero (Solbes, 2013) ${ }^{28}$.

\section{CONSIDERACIONES FINALES}

Este trabajo nació con el objetivo de dar respuesta a tres preguntas de investigación relativas, respectivamente, a los motivos que condujeron al presidente Rodríguez Zapatero a promover la OEP, al modo en que la convirtió

24 Javier Vallés había sido el director del Departamento de Política Económica de la OEP entre 2005 y 2008.

25 «El poder económico en la sombra: Álvaro Nadal, el hombre de confianza de Rajoy». Eleconomista.es. 25-10-2012. Disponible en: https://bit.ly/3jp2LLD.

26 «Sánchez elimina la Oficina Económica de Moncloa». Cinco Días. 19-06-2018. Disponible en: https://bit.ly/3y742LE.

27 Aunque en informaciones periodísticas posteriores a la investidura de Pedro Sánchez se hace alusión a la Oficina Económica, ninguna reorganización del centro presidencial acometida hasta el momento ha significado la recuperación de dicha instancia. Sí existen actualmente órganos superiores llamados a desempeñar funciones homologables a las desarrolladas en el pasado por la OEP, como la Secretaría General de Asuntos Económicos y G20, y la Oficina Nacional de Prospectiva Nacional y Estrategia de País a Largo Plazo. No obstante, la titularidad de ninguna de ellos es ejercida por personas con rango de secretario de Estado (Real Decreto 1177/2020), contrariamente a lo que ocurría con la OEP en el primer mandato de Zapatero y durante la presidencia de Mariano Rajoy (Real Decreto 1094/2011).

28 A juicio de Solbes, en vez de seguir la regla no escrita (atribuida a Olof Palme) de apoyar siempre al ministro de Economía, Zapatero decidió actuar como un mediador entre él y el resto del Gobierno (Solbes, 2013: 269). 
en una instancia con capacidad para intervenir en la toma de decisiones y al impacto que tal hecho tuvo en la autonomía de su responsable del Fisco Pedro Solbes. Los hallazgos realizados en relación a las preguntas de investigación formuladas en un principio nos permiten afirmar, en primer lugar, que la creación de la OEP fue un proceso impremeditado, en el marco de una estrategia de autorreforzamiento presidencial que tenía por meta original el nombramiento de Miguel Sebastián como ministro de Economía, algo que finalmente no ocurrió debido a distintos condicionamientos de diversa índole. A pesar de ello Sebastián, amigo de Zapatero y su gurú económico en la oposición, no solo coincidió con el dirigente socialista en la conveniencia de permanecer junto a él en calidad de consejero presidencial, sino que además le persuadió de la utilidad de dotar de autonomía al soporte de asesoramiento al jefe de Gobierno en materia económica.

Creada la OEP, esta se convirtió en un actor importante dentro del aparato gubernamental por los recursos de personal con que se dotó. No obstante, el factor más importante en este sentido fue la validación que Zapatero hizo de dicho órgano como instancia cualificada para alumbrar iniciativas políticas a través de sucesivas decisiones: adjudicación al director de la OEP Miguel Sebastián de rango de secretario de Estado con capacidad para participar en la Comisión Delegada de Asuntos Económicos; nombramiento de Sebastián como coordinador del Gobierno español para la Estrategia de Lisboa y responsable del Programa Nacional de Reformas; reconocimiento a la OEP del liderazgo en la Unidad Permanente de Lisboa; adjudicación a la OEP de vocalías en Comisiones Interministeriales, etc. Por otro lado, Zapatero involucró a la OEP en el diseño de políticas públicas por su manera de trabajar, que entre otras conllevaba la petición de ideas y propuestas a todos los actores integrantes del Gobierno.

El protagonismo alcanzado por la OEP desplazó al Ministerio de Economía en algunos ámbitos específicos, como por ejemplo la política europea. De tal cosa no cabe inferir, sin embargo, que la influencia del Tesoro se viera restringida de una manera sistemática y general por la OEP. Prueba de ello sería el liderazgo indiscutible de Solbes en la Comisión Delegada de Asuntos Económicos o, más específicamente, que el ministro de Economía vetara la reforma fiscal intelectualmente patrocinada por Sebastián y recogida en el programa electoral del PSOE. Un episodio como el de los 400 euros, en que cierta medida fiscal es concebida por la OEP a petición de Zapatero y contra el criterio de Solbes, ha de interpretarse como un hecho aislado, revelador en todo caso del límite que la presidencialización supone para el responsable de las cuentas públicas no por la actividad de los asesores del jefe de Gobierno, sino por el rol que el premier termina atribuyéndose a sí mismo. 
En otro plano, este estudio de caso ha servido asimismo para contrastar en qué medida la creación de la OEP, entendida como reforma de la estructura de apoyo y asesoramiento del presidente del Gobierno, reprodujo fenómenos apreciados en procesos análogos. Así, el análisis de la evidencia generada nos permite afirmar que la remodelación del centro presidencial aquí examinada acogió, de manera inequívoca, la expresión de tres tendencias generales observadas en las transformaciones experimentadas por los core executives en aquellos ańos: la personalización (pues la creación de la OEP solo puede explicarse a partir de la figura de Sebastián y de su relación personal con Zapatero), el crecimiento (expresado en la incorporación al centro presidencial de casi tres decenas de economistas) y la hibridación.

El tercero de los fenómenos no se colige de una definición deficiente o parcial de las competencias de la OEP, o de que esta funcionara inesperadamente como un órgano emisor de iniciativas políticas, sino más bien de dinámicas generadas por el tipo de relación establecida con aquella por actores tales como el presidente Zapatero, los ministerios o las grandes empresas. Fueron estos, al demandar apoyo de la OEP, los que propiciaron un marco de funcionamiento marcado por la confusión de las fronteras entre las distintas fuentes de apoyo y asesoramiento, en detrimento del protagonismo ejercido tradicionalmente por el Ministerio de Economía y Hacienda.

El caso examinado en estas páginas se desvía de las tendencias generales, sin embargo, en lo concerniente a la institucionalización. Y es que la OEP adquirió un renovado estatus con Mariano Rajoy en la Presidencia del Gobierno, tras devaluarse en el segundo mandato de Zapatero, para finalmente desaparecer con la llegada al poder de Pedro Sánchez. Dicho en otras palabras, como estructura de apoyo al jefe del Ejecutivo, la OEP se probó una instancia especialmente vulnerable a las reorganizaciones acometidas por los sucesivos inquilinos de Moncloa en sus respectivos centros presidenciales. A pesar de su accidentado devenir, el origen marcadamente tecnocrático de la OEP, configurada inicialmente con la incorporación de casi tres decenas de economistas sin afiliación partidista, constituye un fenómeno singular cuya eventual continuidad en el tiempo merece una investigación específica. No en balde, la tecnocratización pudiera ser - junto al crecimiento, la personalización, la institucionalización y la hibridación — otra tendencia característica de las transformaciones operadas en las últimas décadas en los core executives de las democracias avanzadas.

Finalmente puede decirse que, desde una perspectiva global, el presente trabajo contribuye a resolver una carencia existente en el estudio del Gobierno en España, pues la pretendida conflictividad entre los asesores económicos del presidente y el ministro de Economía constituye un lugar común de la literatura, aunque esta cuestión no haya sido hasta ahora estudiada específicamente 
ni se hayan generado nunca evidencias para sostener tal extremo. El valor ańadido de la presente contribución se sustenta, en este sentido, en la información provista por las personas entrevistadas en el desarrollo de nuestra investigación, pues sus testimonios nos han permitido reconstruir los procesos que condujeron a la creación de la OEP, así como el tipo de relaciones establecidas entre este órgano y el resto de actores del core executive, habilitando una lectura que trasciende las prevalecientes interpretaciones convencionales. Por otro lado, las entrevistas han revelado una disputa por el relato acerca de lo que significó la OEP durante el primer Gobierno de Zapatero, correspondiendo las visiones más críticas a quienes podrían considerarse miembros de la vieja guardia. Este hecho sugiere que la hipótesis de la interferencia quizá encubra rivalidades intrapartidistas del pasado, emergiendo consecuentemente como eventual línea de investigación el impacto sobre el funcionamiento del core executive, real o percibido, de las tensiones dentro del partido del Gobierno.

\section{Bibliografía}

Aizpeolea, L. R. (2004). Ciudadano Zapatero. Madrid: Espejo de Tinta.

Blondel, J. (1991). Ministers of finance in Western Europe: A special career? European University Institute SPS. Working Paper, 91-11.

— , Müller-Rommel, F. y Malová, D. (2007). Governing new European democracies. New York: Palgrave MacMillan. Disponible en: https://doi.org/10.1057/9780230800595.

Bonvecchi, A. (2018). De la competencia a la centralización, ida y vuelta: la participación de la presidencia en la conducción de la política económica en Argentina, 1944-2005. En J. Lanzaro (coord.). Centro presidencial. Presidencias y centros de gobierno en América Latina, Estados Unidos y Europa (pp. 77-113). Madrid: Tecnos.

Bruch, M. y Holliday, I. (2004). The Blair government and the core executive. Government and Opposition, 39 (1), 1-21. Disponible en: https://doi.org/10.1111/j.0017-257x. 2004.00029.x.

Chari, R. y Heywood, P. M. (2009). Analysing the policy process in democratic Spain. West European Politics, 32 (1), 26-54. Disponible en: http://doi.org/10.1080/01402380802509800.

Closa, C. (2009). Much ado about little: continuity and change in the European Union policy of the Spanish socialist government (2004-8). South European Society and Politics, 14 (49), 503-518. Disponible en: http://doi.org/10.1080/13608740903503878.

Considine, J. y Reidy, T. (2008). The influence of finance ministers: lessons from the Twentieth century Ireland and the United Kingdom. Administration, 56 (1), 57-84.

Deakin, N. y Parry, R. (2000). The Treasury and social policy: the contest for control of welfare strategy. Houndmills, Basingstoke: Macmillan. Disponible en: https://doi.org/10.1057/ 9780333982341.

Dunleavy, P. y Rhodes, R. A. W. (1990). Core executive studies in Britain. Public Administration, 68, 3-28. Disponible en: https://doi.org/10.1111/j.1467-9299.1990.tb00744.x. 
Elgie, R. (2011). Core executive studies two decades on. Public Administration, 89 (1), 64-77. Disponible en: https://doi.org/10.1111/j.1467-9299.2011.01899.x.

Estefanía, J. (2007). La larga marcha. Medio siglo de politica (económica) entre la Historia y la memoria. Barcelona: Península.

García Abad, J. (2010). El Maquiavelo de León. Madrid: La Esfera de los Libros.

Garrido, A. y Martínez, M. A. (2018). ¿Poder duro o poder blando? El Gabinete del presidente del Gobierno en Espańa. Revista de Estudios Políticos, 180, 163-195. Disponible en: https://doi.org/10.18042/cepc/rep.180.06.

Genovese, M. A. (2004). Encyclopedia of the American Presidency. New York: Facts on File.

Heffernan, R. (2003). Prime ministerial predominance? Core executive politics in the UK. British Journal of Politics and International Relations, 5 (3), 347-272. Disponible en: https://doi.org/10.1111/1467-856X.00110.

Heywood, P. y Molina, I. (2000). A quasi-presidential premiership: administering the executive summit in Spain. En B. G. Peters, R.A.W. Rhodes y V. Wright (eds.). Administering the summit: administration of the core executive in developed countries (pp. 110-133). London: Macmillan. Disponible en: https://doi.org/10.1007/978-1-349-62797-4_7.

Jaén, E. y Escudier, J. C. (2007). Zapatero «El Rojo». Madrid: Foca.

Kölling, M. (2009). Negociaciones financieras en la Unión Europea: actores e instituciones. Las perspectivas financieras 2007-2013 [tesis doctoral]. Universidad de Zaragoza. Disponible en: https://bit.ly/3h4Ij10.

Lanzaro, J. (2018). Introducción. En Lanzaro, J. (coord.). Centro presidencial. Presidencias y centros de gobierno en América Latina, Estados Unidos y Europa (pp. 13-38). Madrid: Tecnos. Disponible en: https://doi.org/10.46468/18531970.13.1.R4.

Larsson, T. (1993). The role and position of ministers of finance. En J. Blondel y F. MüllerRommel (eds.). Governing together. The extent and limits of joint decision-making in Western European cabinets (pp. 207-222). New York: St. Martin's Press.

Mulas Granados, C. (2007). La Estrategia de Lisboa, el Programa Nacional de Reformas y las políticas de oferta en España. Información Comercial Española, 837, 231-248.

Müller-Rommel, F. (1993). Ministers and the role of the Prime Ministerial Staff. En J. Blondel y F. Müller-Rommel (eds.). Governing together. The extent and limits of joint decision-making in Western European cabinets (pp. 131-152). New York: St. Martin's Press. Disponible en: https://doi.org/10.1007/978-1-349-22936-9_6.

Olías de Lima, B. (1994). Los gabinetes de los presidentes de Gobierno en España. Política y Sociedad, 16, 257-272.

Ortega Álvarez, L. (1991). El Gabinete del Presidente del Gobierno. Documentación Administrativa, 226, 199-244.

Paniagua, J. L. (2018). La Moncloa: una estructura presidencial para el Gobierno de España, 1978-2015. En J. Lanzaro (coord.). Centro presidencial. Presidencias y centros de gobierno en América Latina, Estados Unidos y Europa (pp. 393-437). Madrid: Tecnos.

Peters, B. G., Rhodes, R. A. W. y Wright, V. (eds.) (2000). Administering the summit: administration of the core executive in developed countries. London: Macmillan. Disponible en: https://doi.org/10.1007/978-1-349-62797-4.

Poguntke, T. y Webb, P. (2005). The presidentialization of politics in democratic societies: a framework for analysis. En T. Poguntke y P. Webb (eds.). The presidentialization of 
politics: a comparative study of modern democracies (pp. 1-25). Oxford: Oxford University Press. Disponible en: https://doi.org/10.1093/0199252017.001.0001.

Rodríguez Teruel, J. (2020). Executive politics in Spain. En D. Muro e I. Lago (eds). The Oxford Handbook of Spanish politics (pp. 190-209). Oxford: Oxford University Press. Disponible en: https://doi.org/10.1093/oxfordhb/9780198826934.013.12.

Royo, S. (2009). Reforms betrayed? Zapatero and continuities in economic policy. South European Society and Politics, 14 (4), 435-451. Disponible en: https://doi.org/10.1080/ 13608740903503837.

Santamaría, J. (2007). Las elecciones generales de 2004 en su contexto. En J. R. Montero, I. Lago y M. Torcal (eds.). Elecciones generales 2004 (pp. 31-63). Madrid: Centro de Investigaciones Sociológicas.

Thain, C. y Wright, M. (1995). The Treasury and Whitehall: the planning and control of public expenditure, 1976-1993. Oxford, Clarendon Press. Disponible en: https://doi. org/10.1093/acprof:oso/9780198277842.001.0001.

Tiernan, A. (2006). Advising Howard: interpreting changes in advisory and support structures for the Prime Minister of Australia. Australian Journal of Political Science, 41 (3), 309-324. Disponible en: https://doi.org/10.1080/10361140600848937.

Solbes, P. (2013). Recuerdos: 40 años de servicio público. Barcelona: Deusto.

Verge, T. (2007). Partidos y representación política: las dimensiones del cambio en los partidos politicos españoles, 1976-2006. Madrid: Centro de Investigaciones Sociológicas. 